\title{
Surface Materials of the Viking Landing Sites
}

\author{
Henry J. Moore, ${ }^{1}$ Robert E. Hutton, ${ }^{2}$ Ronald F. Scott,${ }^{3}$ Cary R. Spitzer,,${ }^{4}$ \\ AND RichaRd W. SHORTHILL ${ }^{5}$
}

\begin{abstract}
Martian surface materials viewed by the two Viking landers (VL-1 and VL-2) range from fine-grained nearly cohesionless soils to rocks. Footpad 2 of VL-1, which landed at $2.30 \mathrm{~m} / \mathrm{s}$, penetrated $16.5 \mathrm{~cm}$ into very fine grained dunelike drift material; footpad 3 rests on a rocky soil which it penetrated $\approx 3.6 \mathrm{~cm}$. Further penetration by footpad 2 may have been arrested by a hard substrate. Penetration by footpad 3 is less than would be expected for a typical lunar regolith. During landing, retroengine exhausts eroded the surface and propelled grains and rocks which produced craters on impact with the surface. Trenches excavated in drift material by the sampler have steep walls with up to $6 \mathrm{~cm}$ of relief. Incipient failure of the walls and failures at the end of the trenches are compatible with a cohesion near $10-10^{2} \mathrm{~N} / \mathrm{m}^{2}$. Trenching in rocky soil excavated clods and possibly rocks. In two of five samples, commanded sampler extensions were not achieved, a situation indicating that buried rocks or local areas with large cohesions $(\geq 10$ $\mathrm{kN} / \mathrm{m}^{2}$ ) or both are present. Footpad 2 of VL-2, which landed at a velocity between 1.95 and $2.34 \mathrm{~m} / \mathrm{s}$, is partly on a rock, and footpad 3 appears to have struck one; penetration and leg strokes are small. Retroengine exhausts produced more erosion than occurred for VL-1 owing to increased thrust levels just before touchdown. Deformations of the soil by sampler extensions range from doming of the surface without visible fracturing to doming accompanied by fracturing and the production of angular clods. Although rocks larger than $3.0 \mathrm{~cm}$ are abundant at VL-I and VL-2, repeated attempts to collect rocks $0.2-1.2 \mathrm{~cm}$ across imbedded in soil indicate that rocks in this size range are scarce. There is no evidence that the surface sampler of VL-2, while it was pushing and nudging rocks $\approx 25 \mathrm{~cm}$ across, spalled, chipped, or fractured the rocks. Preliminary analyses of surface sampler motor currents $(\approx 25 \mathrm{~N}$ force resolution) during normal sampling are consistent with cohesionless frictional soils $\left(\phi \approx 36^{\circ}\right)$ or weakly cohesive frictionless soils $\left(C<2 \mathrm{kN} / \mathrm{m}^{2}\right)$. The soil of Mars has both cohesion and friction.
\end{abstract}

\section{INTRODUCTION}

Viking lander 1 (VL-1) landed on Chryse Planitia on July 20, 1976, and was followed by Viking lander 2 (VL-2), which landed on Utopia Planitia, $6500 \mathrm{~km}$ away from VL-1, on September 3, 1976. Both landers successfully completed their primary missions on November 15, 1976, prior to solar conjunction. Extensive activities for VL-1 lasted 41 Martian days (sols) (the duration of 1 sol is about 24.66 hours) and continued at a reduced level for an additional 64 sols. Extensive activities for VL-2 lasted 60 sols. Both landers survived solar conjunction and are currently performing their extended missions [Soffen, 1976]. This report is concerned with the Physical Properties Investigation of the Martian surface materials based on lander activities during their primary missions. Preliminary results have been reported previously [Shorthill et al., $1976 a, b, c]$.

The objective of the Physical Properties Investigation is to further man's understanding of the Martian environment by determining the physical properties of the surface materials [Shorthill et al., 1972] within the constraints defined in the Viking '75 Project Mission Definition [National Aeronautics and Space Administration, 1970, p. 32].

The primary objective of the mission is the exploration of Mars with an emphasis on the search for life. Three analytical instruments and experiments designed to meet the objective were carried to the surface of Mars: Biology, Molecular Analysis, and Inorganic Chemical Analysis. All of these experi-

${ }^{1}$ U.S. Geological Survey, Menlo Park, California 94025.

${ }^{2}$ Applied Mechanics Laboratory, TRW Systems Group, Redondo Beach, California 90278.

${ }^{3}$ Department of Engineering and Applied Sciences, California Institute of Technology, Pasadena, California 91125

- NASA Langley Research Center, Hampton, Virginia 23665.

${ }^{5}$ Geospace Sciences Laboratory, University of Utah Research Institute, Salt Lake City, Utah 84108 .

Copyright $(\subset) 1977$ by the American Geophysical Union.

Paper number 7 S0447. ments required the use of the Viking surface sampler to obtain samples on a priority basis. Thus physical properties of the Martian surface materials have been estimated insofar as possible from normal activities of the surface sampler while it was acquiring samples for these experiments and other spacecraft activities. Optimal use of the surface sampler for the Physical Properties Investigation awaits exhaustion of the capacities of the analytical experiments sometime in the extended mission.

\section{General Description of the Landing Sites}

\section{Chryse Planitia}

Panoramas taken by VL-1 are reminiscent of both terrestrial aeolian and lunar scenes. Large tracts of cross-bedded drifts of wind-eroded dunelike structures are superposed on rocky terrain [Mutch et al., 1976a]. The terrain is similar in appearance to the immediate surroundings of the Surveyor 7 landing site of the moon, and both have similar size-frequency distributions of rocks and blocks [Mutch et al., 1976b]. The surface in the immediate vicinity of VL-1 consists of an area underlain by very fine grained material (informally named Sandy Flats) and an area of rocks set in a matrix of finer-grained material (includes Rocky Flats) (Figure $1 a$ ). Finer-grained materials, which occupy $12-14 \%$ of the sample field, are probably the same material as those in the drifts and will be called drift material. Small grains and fragments propelled by engine exhausts during landing have produced chains of elongate rimmed to rimless craters by impact with the drift material. Elongation of the craters and alignment of the chains are parallel to radials from the three retroengines.

Footpad 2 penetrated drift material $16.5 \mathrm{~cm}$, open fissures and both monoclinal and anticlinal flexures of the surface thus being produced near the footpad (Figure $2 b$ ). Penetration by footpad 2 was so large that it was completely covered by drift material. Drift material increases in thickness from the mapped boundary with the rocky area in the sample field toward footpad 2 (Figure $1 a$ ). 


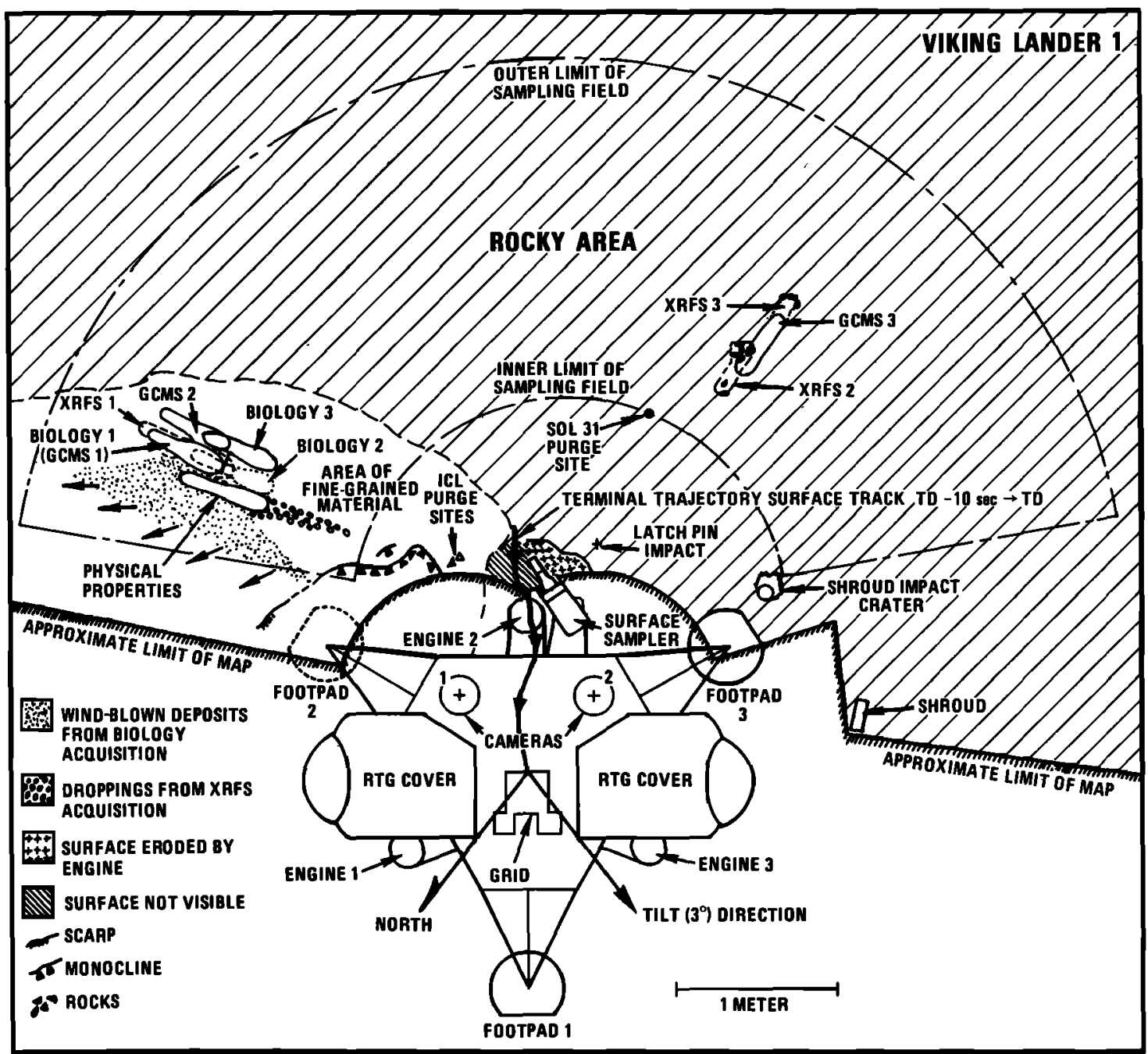

Fig. la

Fig. 1. Plan views of $(a)$ VL-1 and $(b)$ VL-2 showing the landed spacecraft and their orientations, locations of sample sites, selected rocks, and surface disturbances relevant to the Physical Properties Investigation, and the radioisotope thermal generator (RTG); surface sampler activities are summarized in Tables 4 (VL-1) and 5 (VL-2). Plan views are projected in the lander coordinate system.

Rocky materials occupy most of the sample field. Roughly $25 \%$ of the rocky area is exposed rocks, both on and partially beneath the surface. These rocks and exposures of rocks vary from a few centimeters to several tens of centimeters across within the sample field. Between the rocks, fine-grained material is commonly present as thick wind tails on the southern sides of rocks and as thinner deposits between the rocks. Wind tails are elongated in southerly directions. Small deflation hollows produced by wind erosion are common on the northern sides of rocks. Locally, loose fine-grained materials have been stripped away, and a residue of clods, small fragments, and tips of larger buried clods and rocks $0.5 \mathrm{~cm}$ or so across has thus been left. Footpad 3 rests on these rocky materials and, judging from footpad shadows assumed to be cast on a level surface, has penetrated the surface about $3.6 \mathrm{~cm}$ (Figure $2 a$ ). Near the spacecraft (Figure $1 a$ ), retroengine exhausts have eroded the surface, dislodged small rocks, produced fillets of debris on the sides of rocks facing retroengine 2, and propelled small grains and fragments that produced small craters upon impact with the surface. Near retroengine 2, fines have been stripped away to expose a horizontal planar surface underlain by more cohesive fractured material (Figure $2 a$ ).

Orbital pictures of the Chryse region taken by the Viking 1 orbiter and earth-based radar echoes from the region are compatible with the VL-1 panorama [Tyler et al., 1976]. The pictures reveal that the uppermost Martian surface has been modified by the wind and impact cratering. Small craters a few hundred meters in diameter have excavated dark material by the ejection of debris and were subsequently modified by the wind which produced bright wind tails on the southwestern sides of the craters and dark northeast flanks by erosion. Radar reflection coefficients are larger than average lunar ones; surface roughness is comparable to that of the rougher lunar maria. Thus both aeolian features and rocky surfaces seen by VL-1 are consistent with the orbiter pictures and echoes from earth-based radars.

\section{Utopia Planitia}

In contrast with Chryse Planitia, deposits of cross-bedded drifts are virtually absent at Utopia Planitia, and the site is uniformly rocky. The rocky eroded appearance of the VL-2 site is consistent with orbital pictures of the site in particular and the region of Mars between $44^{\circ} \mathrm{N}$ and $48^{\circ} \mathrm{N}$ in general. The surface materials in the sample field (Figure $1 b$ ) can be described as blocks and fragments set in a matrix of finergrained material. Typically, the rocks and blocks appear to be 


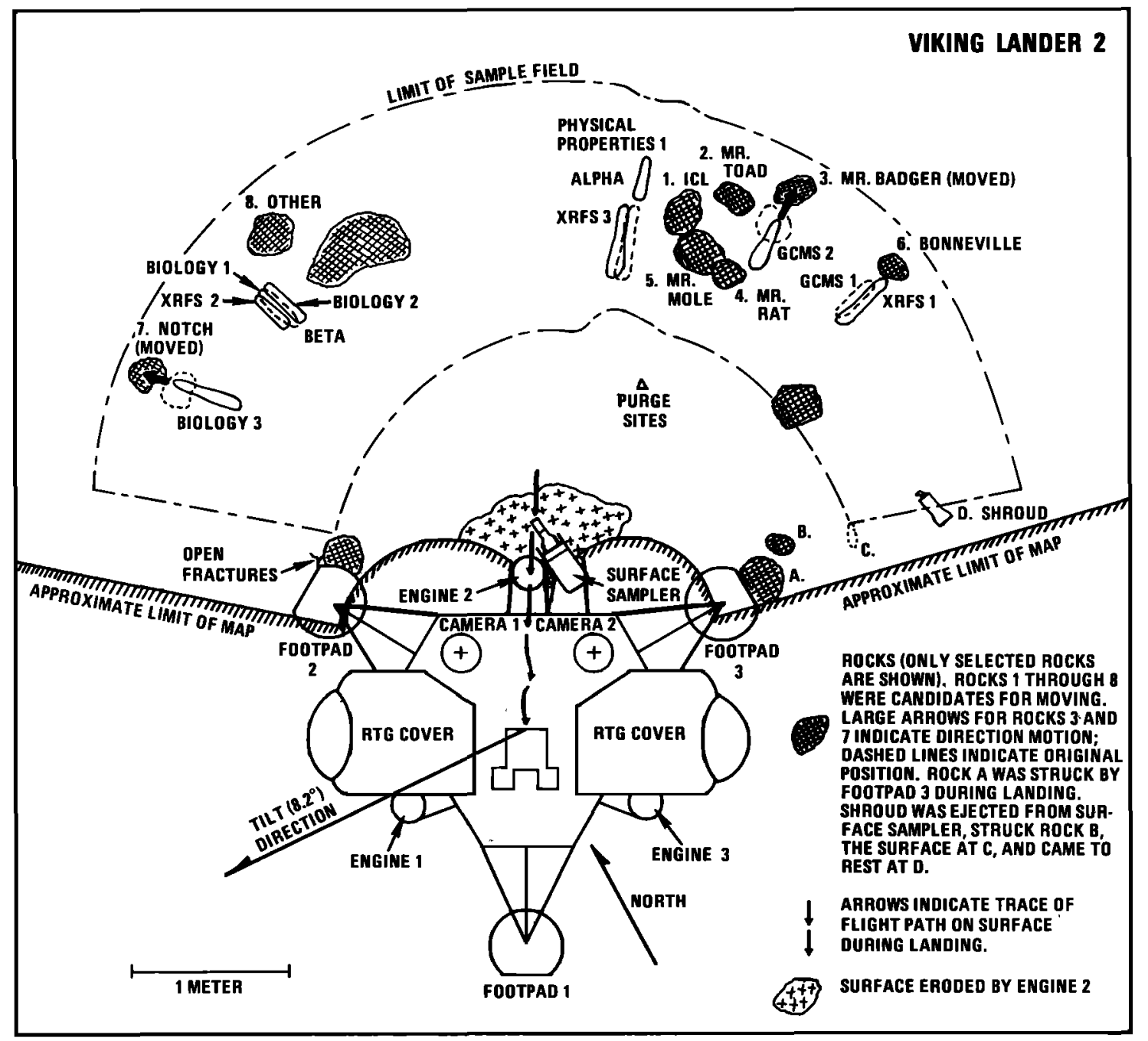

Fig. $1 b$

vesicular. Large rocks and blocks are approximately twice as abundant as those at the VL-1 site [Mutch et al., 1976b], so abundant that they profoundly affected analysis of the landing data for physical properties and the subsequent sampling activities. Blocks within the sample field attain dimensions of $0.65 \times 0.23 \mathrm{~m}$, and $16-20 \%$ of the area is covered by rocks a few centimeters across and larger. Locally, beyond the sample field, small dunes in linear depressions or rilles have been pitted by rocks propelled by engine exhausts. Their form and orientation indicate a local wind direction near $320^{\circ}$. Finergrained materials between the rocks are present as fillets and small drifts, but most surfaces have been stripped of fines to expose a weak platy crust, blocky fractured soil, and knobby surfaces of small clods and rocky fragments. Unlike the VL-1 site, where the sample field could readily be divided into two types of material, Utopia Planitia is more uniform. The sample field near footpad 3 and the ejected shroud is relatively rock free, however (Figure $1 b$ ). The footpads probably struck rocks on landing (footpad 1 is not visible) and have penetrated the surface a very small amount. A rock $22 \mathrm{~cm}$ across occupies part of the projected area beneath retroengine 2 (Figure $1 b$ ).

\section{LANDING}

\section{Descent}

Descent trajectories of both landers passed over the sample fields. Ten seconds before touchdown, VL-1 was $27 \mathrm{~m}$ above the surface traveling in the direction of leg 1 (in the landed configuration), and the body center was approximately $1.5 \mathrm{~m}$ uprange from its final location (Figure $1 a$ ). Thus the sample field was exposed to engine exhaust impingement to a greater degree than it would have been if the lander had approached from any other direction. One second before touchdown, VL- 1 was descending at $2.44 \mathrm{~m} / \mathrm{s}$ and moving about $0.15 \mathrm{~m} / \mathrm{s}$ in a horizontal direction toward leg 1 . A linear least squares fit to velocity increments measured by the inertial reference unit (IRU) during the last $2 \mathrm{~s}$ indicated a touchdown velocity of $2.30 \mathrm{~m} / \mathrm{s}$. Roll about the vertical axis was only $0.25^{\circ} / \mathrm{s}$. Inflight tilt at touchdown required that leg 2 was about $1 \mathrm{~cm}$ lower and leg 1 was about $1.5 \mathrm{~cm}$ higher than leg 3 . When these requirements were combined with local surface tilt and topography, leg 2 touched down first, followed by leg 3 and then leg 1.

At $10 \mathrm{~s}$ before touchdown, VL-2 was $26 \mathrm{~m}$ above the surface and about $1.7 \mathrm{~m}$ uprange of its final location. It too passed over the sample field moving in the direction of leg 1 . VL-2 was descending at $2.44 \mathrm{~m} / \mathrm{s} 1 \mathrm{~s}$ before touchdown. A linear least squares fit to velocity increments from the inertial reference unit during the last $2 \mathrm{~s}$ indicated a touchdown velocity of 2.34 $\mathrm{m} / \mathrm{s}$. Engine thrust levels increased during the last $0.4 \mathrm{~s}$ and probably reduced the velocity to $1.95 \mathrm{~m} / \mathrm{s}$. This is discussed in the following section. At touchdown the inflight tilt required that leg 1 was $3.5 \mathrm{~cm}$ lower and leg 2 was $7 \mathrm{~cm}$ higher than leg 
a
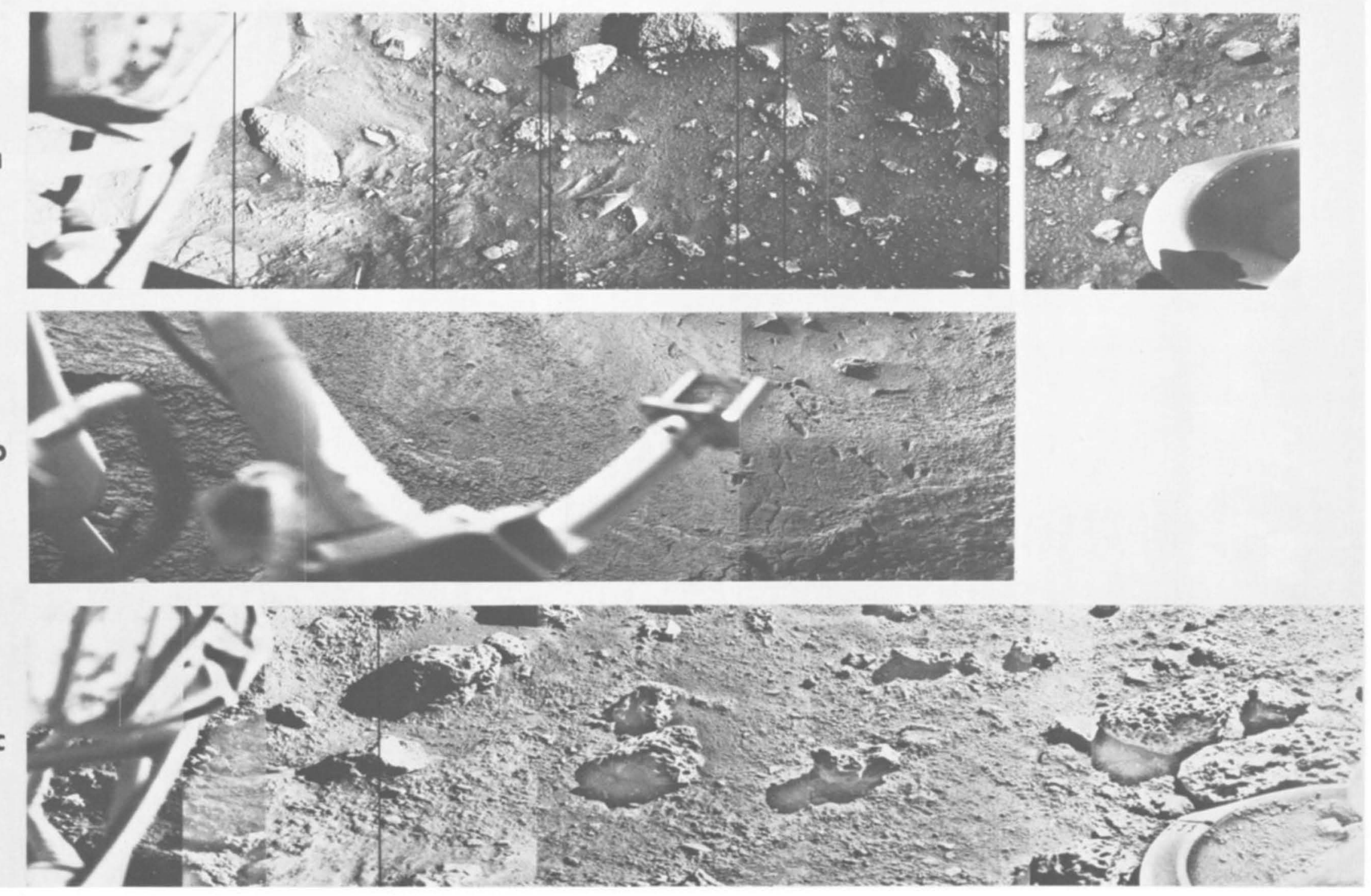

Fig. 2. Mosaic showing footpads and engine exhaust erosion of VL-1 and VL-2. (a) Footpad 3 of VL-1 has penetrated rocky material $\approx 3.6$ $\mathrm{cm}$. Some of the rocks were moved by engine exhausts; the crater produced by shroud impact is near footpad 3. Note the area stripped by engine exhausts to the left. (b) Footpad 2 of VL-1 has penetrated drift material and is buried. Note chains of small elongate craters produced by grains and fragments propelled by engine exhausts. Chains are alined along radials from engines. (c) Footpad 3 of VL-2; the footpad probably struck rock to the left of the footpad. The rock beyond the footpad was struck by the ejected shroud. Note the ridges, grooves, and fragments moved by engine exhaust gases to the left. 
TABLE 1. Touchdown Parameters for Viking 1 and 2 Landers

\begin{tabular}{lcc}
\hline \multicolumn{1}{c}{ Parameter } & Viking I & Viking 2 \\
\hline Touchdown velocity, m/s & & \\
$\quad$ IRU & 2.30 & 2.34 \\
Engine thrusts & 2.44 & 1.95 \\
Latitude, ${ }^{\circ} \mathrm{N}$ & 22.46 & 47.97 \\
Longitude, ${ }^{\circ} \mathrm{W}$ & 48.01 & 225.67 \\
Leg 1 stroke, by stroke gauge, cm & 7.0 & $2.5-3.2$ \\
Leg 2 stroke, cm & & \\
$\quad$ By stroke gauge & 3.2 & 7.6 \\
$\quad$ By footpad travel & 2.8 & 7.6 \\
Leg 3 stroke, cm & 8.3 & 1.3 \\
$\quad$ By stroke gauge & 8.3 & 1.3 \\
$\quad$ By footpad travel & $\ldots .$. & $\ldots$ \\
Footpad 1 penetration (not visible) & 16.5 & 2.5 \\
Footpad 2 penetration, cm & 3.6 & $0-0.3$ \\
Footpad 3 penetration, cm & 321.9 & 209.1 \\
Leg azimuth (east of north), deg & 3.0 & 8.2 \\
Tilt angle (relative to gravity vector), deg & 285.2 & 277.7 \\
Tilt azimuth (east of north), deg & 611 & 611 \\
Landed mass, kg & & \\
\hline
\end{tabular}

3. The local surface tilt indicated that leg 3 should have touched down first, followed by leg 1 and then leg 2 .

\section{Touchdown}

A comparison of the leg strokes on the two landers indicates that the average leg stroke on VL-1 was larger than that on VL-2. The strokes of legs 2 and 3 determined from stroke gauges and leg travel for VL-2 are the same and imply that the load limiters at the secondary strut attachment did not yield, so energy dissipation was essentially due to irreversible crushing of the primary strut honeycomb tube core cartridge. This suggested that a larger fraction of the remaining energy must have been removed by the penetration of the footpads into the Martian surface on lander 2, but comparison of the footpad penetrations of the two spacecraft indicates that the opposite is true (touchdown parameters are given in Table 1).

The problem can be resolved by considering data on valve settings of the descent engines just prior to VL-2 touchdown. During the last $0.43 \mathrm{~s}$ before touchdown, thrust levels of engines 1, 2, and 3 increased by about 14,81 , and $91 \%$, respectively [Martin Marietta Corporation, 1976]. The impulse associated with the total thrust level increase is about $1360 \mathrm{~N} \mathrm{~s}$ and produced an incremental velocity change of about $0.49 \mathrm{~m} / \mathrm{s}$. This makes the velocity of VL-2 at surface contact near 1.95 $\mathrm{m} / \mathrm{s}$ and smaller than the nominal descent value of $2.44 \mathrm{~m} / \mathrm{s}$ existing before the thrust suddenly increased. This smaller velocity is compatible with the smaller leg strokes on VL-2. Energy balance calculations indicate that the ratios of the energies absorbed by the primary strut stroking to the initial kinetic energies of VL-1 and VL-2 are 66 and $51 \%$, respectively. More detailed energy balance calculations will be made at a later date.

\section{Footpad-Surface Interactions}

Footpad penetrations and leg strokes of VL-1 show that the two materials there have markedly differing mechanical properties. Footpad 3 of VL-1 only penetrated rocky material about $3.6 \mathrm{~cm}$, whereas footpad 2 penetrated $16.5 \mathrm{~cm}$ and was buried in drift material (Figures $2 a$ and $2 b$ ). Significantly different mechanical properties of the two materials are indicated because velocities of the two footpads at touchdown should be nearly the same, although footpad 2 may have touched first.
Footpad penetration cannot entirely resolve the mechanical properties of drift material because drift material is superposed on rocky material and thins to a feather edge at the mapped boundary of the two, so it is entirely possible that a hard substrate or buried rock caused penetration to cease. On the other hand, excavation of a trench $23 \mathrm{~cm}$ deep counterclockwise of previous trenches during the extended mission encountered no difficulty; a 15-cm rock was excavated, however. Footpad interactions with the surface by VL-2 are problematic. Footpad 3 of VL-2 penetrated $0.3 \mathrm{~cm}$ or less because of the reduced velocity, and it probably struck a rock at touchdown. Footpad 2 of VL-2 penetrated about $2.5 \mathrm{~cm}$, judging from shadows assumed to be cast on a level planar surface, and it too may have struck a rock at touchdown.

Although results for VL-2 are difficult to interpret, footpad-surface material interactions by VL-1 provide valuable insight on the contrasting physical properties of the materials when the observations are combined with experimental data. The Viking footpad is an inverted frustum of a cone capped by a spherical segment, with an irregular skirt around the base (Figure 3). Calculations for VL-1 indicate that the total work done by plastic deformation of the honeycomb tube core, frictional sliding of the footpads, soil penetration, and the decaying engine thrusts during touchdown becomes equal to the kinetic energy at surface contact plus the change of potential energy from surface contact to the final rest position, when the effective coefficient of sliding friction is in the range of 0.3-0.5. If these coefficients and the force-stroke characteristics [Martin Marietla Corporation, 1973a] are used, forces on the footpads during touchdown are $6.8-7.6 \mathrm{kN}$, leg $1 ; 4.6-5.4$ $\mathrm{kN}$, leg 2; and 8.2-9.2 kN, leg 3. Comparison of these forces and the corresponding penetrations with results from essentially static tests of a s-scale footpad in three soil simulants (Table 2), appropriately scaled for the Viking lander on Mars (R. F. Scott, unpublished data, 1976), shows the contrasting difference in penetration resistance of drift material and rocky material (Figure 4). The force and penetration for footpad 3 of VL-1 lie to the upper left of the curves for the three soils and imply a stronger material. The force and penetration for footpad 2 of VL-1 lie to the lower right of the curves for the three soils and imply that the drift material is very weak and penetrable.

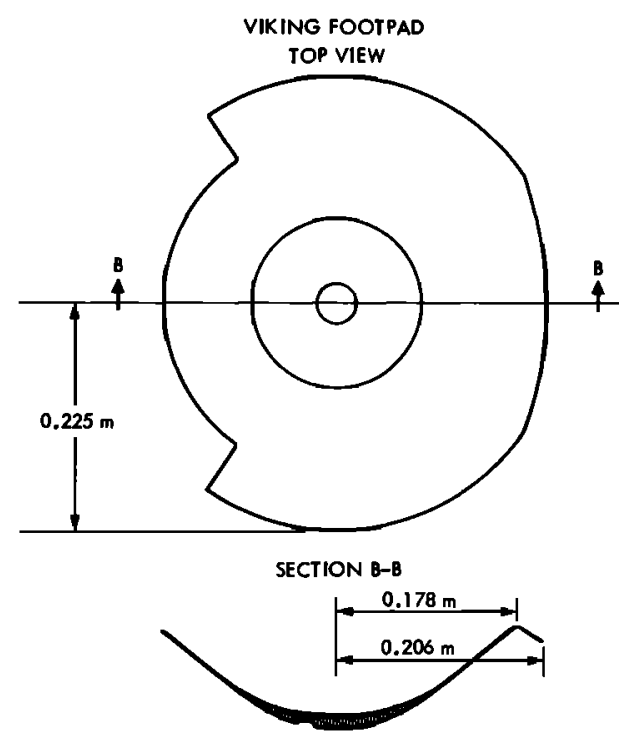

Fig. 3. Shape and dimensions of footpad of Viking lander. 
TABLE 2. Mechanical Properties of Soil Simulants Used in Footpad Tests

\begin{tabular}{|c|c|c|c|c|c|}
\hline Test & Simulant & $\begin{array}{l}\text { Density, } \\
\mathrm{kg} / \mathrm{m}^{\mathrm{s}}\end{array}$ & $\begin{array}{c}\text { Cohesion,* } \\
\mathrm{kN} / \mathrm{m}^{2}\end{array}$ & $\begin{array}{l}\text { Angle of } \\
\text { Internal } \\
\text { Friction,* } \\
\text { deg }\end{array}$ & Grain Size \\
\hline $\begin{array}{l}\frac{5}{8} \text { scale } \\
\frac{3}{8} \text { scale } \\
\frac{3}{8} \text { scale } \\
\text { Full scale } \\
\text { Full scale } \\
\text { Full scale } \\
\text { Reduced } \\
\quad \text { scale }\end{array}$ & $\begin{array}{l}\text { lunar nominal } \\
\text { basalt dune sand } \\
\text { white sand } \\
\text { lunar nominal } \\
\text { lunar nominal } \\
\text { basalt dune sand } \\
\text { lunar nominal }\end{array}$ & $\begin{array}{c}1100-1700 \\
1150-1220 \\
1600-1660 \\
1440 \\
1630 \\
1130-1280 \\
1360 \\
1600 \\
1840\end{array}$ & $\begin{array}{c}0.5-0.6 \\
0-0.1 \\
0.06-0.08 \\
0.5-0.6 \\
0.8-1.0 \\
\ldots\end{array}$ & $\begin{array}{l}40-45 \\
30-40 \\
30-35 \\
35-40 \\
35-40 \\
37-52\end{array}$ & $\begin{array}{l}\text { 4-104 } \mu \mathrm{m} \text {, poorly sorted } \\
0.6-\mathrm{mm} \mathrm{m} \text { man, well sorted } \\
0.21-0.30 \mathrm{~mm} \\
4-10^{4} \mu \mathrm{m} \text {, poorly sorted } \\
4-10^{4} \mu \mathrm{m} \text {, poorly sorted } \\
0.6-\mathrm{mm} \text { mean, well sorted } \\
4-10^{4} \mu \mathrm{m} \text {, poorly sorted } \\
4-10^{4} \mu \mathrm{m} \text {, poorly sorted } \\
4-10^{4} \mu \mathrm{m} \text {, poorly sorted }\end{array}$ \\
\hline
\end{tabular}

*Blank spaces in these columns indicate that values were not actually measured but are similar to the values for the corresponding soil that appear in this table.

Dynamic tests of footpads were done because of the importance of several factors during dynamic loading such as (1) positive pore gas pressures resulting from compression of finegrained materials during dynamic loading [L.V. Clark, 1971], (2) the geometry of the penetrating object [Young, 1967], and (3) the acceleration of gravity [Pyrz, 1969]. Full-scale tests of prototype skirted footpads were conducted in lunar nominal soil beds with two densities and basalt dune sand (Tables 2 and 3) at velocities of $2.44 \mathrm{~m} / \mathrm{s}$ in 1 atm of air [Martin Marietta Corporation, 1971]. In one test, penetration into lunar nominal soil with a density of $1440 \mathrm{~kg} / \mathrm{m}^{3}$ (run 14) [Martin Marietta Corporation, 1971] was an astonishing $26.5 \mathrm{~cm}$, and leg stroke a mere $0.3 \mathrm{~cm}$ (Figure 5). This test result prompted an investigation of footpad penetration in both 5- and 1000-mbar ambient pressures with lunar nominal test beds of densities estimated to be 1360,1600 , and $1740 \mathrm{~kg} / \mathrm{m}^{3}$ (Tables 2 and 3 ) [L. V. Clark, 1971]. These tests at reduced pressure showed that penetrations were functions of the ambient pressure and density of the test soil. Results from the low-pressure tests scaled to the Viking footpads and velocity by using equations developed for low-velocity impacts (see Figure 5 and $L$. $V$. Clark and J. L. MCCarty [1963]) imply a penetration near 15

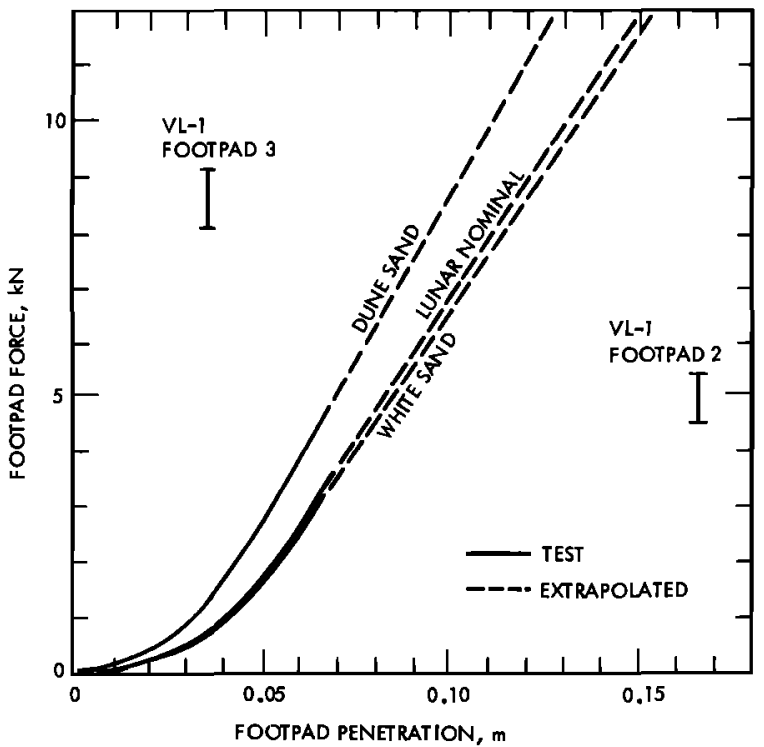

Fig. 4. Force-penetration curves for static loading test of s-scale Viking footpad scaled to the Viking footpads and Mars gravity. $\mathrm{cm}$ for a density of $1360 \mathrm{~kg} / \mathrm{m}^{3}$ and $9 \mathrm{~cm}$ for a density of 1840 $\mathrm{kg} / \mathrm{m}^{9}$ when the mass allotted to a single footpad is $200 \mathrm{~kg}$ (Figure 5). Penetrations calculated for run 14 adjusted for ambient pressure and the scaled low-pressure test data using low-density lunar nominal soil are in fair agreement with the actual penetration of footpad 2 on Mars, and this argues for a density of the drift material near $1300 \mathrm{~kg} / \mathrm{m}^{\mathrm{s}}$. Acceleration of gravity [Pyrz, 1969] (also see Figure 5) may have some effect on the penetration if the cohesion of the soil is low enough. The surface around footpad 2 is not level and flat but slopes about $20^{\circ}$ away from the footpad toward the sample field. Such a slope would reduce penetration resistance [Scott, 1963]. Footpad 3 penetration is consistent with a weakly cohesive material with a density of $2300 \mathrm{~kg} / \mathrm{m}^{3}$ according to Figure 5; however, the small penetration could be the result of a large cohesion and independent of density.

In any event, footpad analyses in comparison with laboratory studies show that there is a significant difference in mechanical properties of the drift and rocky materials. Drift material is somewhat like low-density lunar nominal test soil, whereas the rocky material is much stronger. As was noted previously, none of the analyses entirely resolve the problem of the drift material because the penetration by the footpad could have been arrested by a hard substrate or buried rock. Experiments are planned for the extended mission to learn more about the drift material.

\section{Soil Erosion by Descent Engines}

Exhausts from retroengines of both ldnders eroded the surface materials during landing. Evidence for erosion is found in the first few seconds of pictures taken by the landers $25 \mathrm{~s}$ after touchdown, debris found in unburied footpads, displaced rocks and fragments, chains of elongated craters alined along radials from the retroengines, shallow craters beneath individual en-

TABLE 3. Generalized Footpad Test Conditions

\begin{tabular}{|c|c|c|c|c|}
\hline & \multicolumn{2}{|c|}{ Mars } & \multirow{2}{*}{$\begin{array}{c}\text { Full-Scale } \\
\text { Test }\end{array}$} & \multirow{2}{*}{$\begin{array}{l}\text { Reduced- } \\
\text { Scale Tests }\end{array}$} \\
\hline & VL-I & VL-2 & & \\
\hline $\begin{array}{l}\text { Maximum projected } \\
\text { area of footpad, } \\
\mathrm{m}^{2}\end{array}$ & 0.135 & 0.135 & 0.151 & 0.092 \\
\hline Mass, kg & 200 & 200 & 377 & 52.2 \\
\hline Velocity, $\mathrm{m} / \mathrm{s}$ & 2.30 & 1.95 & 2.44 & 3.48 \\
\hline Pressure, mbar & $\sim 8$ & $\sim 8$ & 1000 & 5 \\
\hline
\end{tabular}




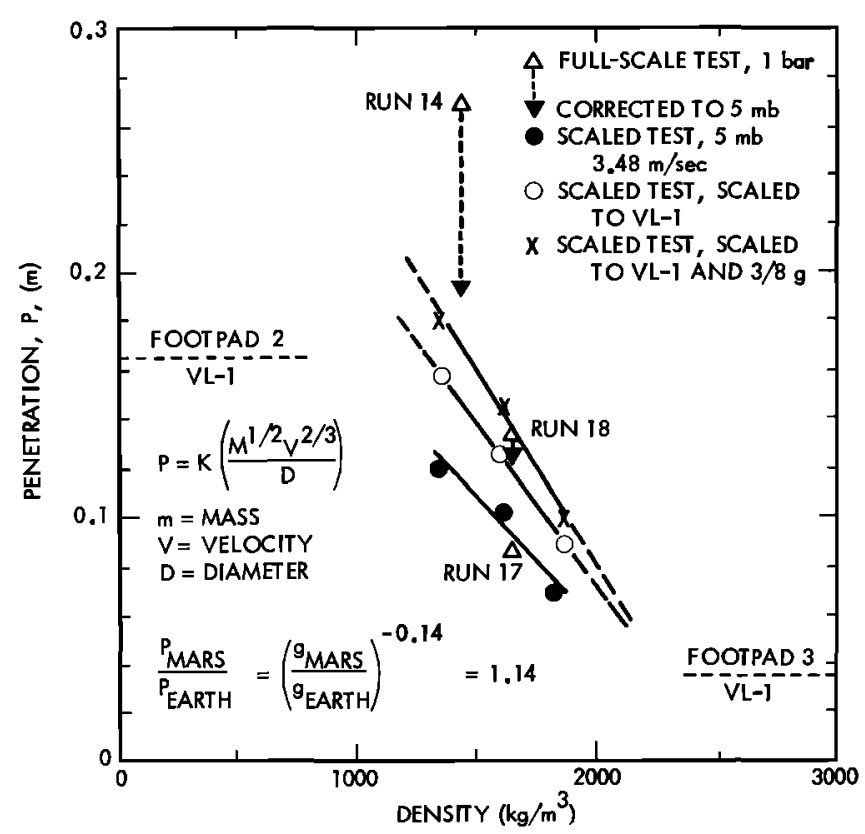

Fig. 5. Density-penetration curves for full-scale tests of Viking prototype footpads in $1 \mathrm{~atm}$ of air (open triangles), reduced-scale tests of footpads in a 5-mbar atmosphere (solid circles), tests of the reduced-scale tests scaled to the Viking lander (VL-1) (open circles), and tests of the reduced-scale tests scaled to the Viking lander and Mars gravity ( $\frac{9}{9} g$ ) (crosses). Penetrations by footpads 2 and 3 of VL-1 are also plotted. The scaled test was adjusted to full scale by using the low-velocity impact penetration equation relating penetration $P$ to mass $M$, velocity $V$, and diameter $D[L . V$. Clark and $J . L$. $M c$ Carty, 1963]. The equation for effect of gravity on penetration is from Pyrz [1969]. Adjustment of full-scale tests for reduced atmospheric pressure is from data of $L . V$. Clark [1971].

gine nozzles viewed through a boom-mounted mirror, and direct views of the area in front of the forward retroengines. The symmetry of erosion by retroengine 2 of VL-2 is more or less radial with a slightly larger extent of erosion toward footpad 3 because of spacecraft tilt (Figure $1 b$ ), whereas this symmetry was not produced by the VL-1 engine because of the contrasting properties of drift material at the left side of the engine (Figure $1 a$ ). Because of spacecraft tilt, erosion to the left of the engine should have been more extensive than it was to the right of the engine.

Vertical bands which appear in the first 40 s or so of the first pictures taken by each lander were produced by coarse particles falling out of a dust cloud generated by engine exhausts [Shorthill et al., 1976a]. This is entirely consistent with site alteration tests with conditions similar to those of the actual landings [Romine et al., 1973]. Two soils were used in separate tests: lunar nominal and basalt dune sand (see Table 2). For the lunar nominal test soil, blowing dust was observed as soon as the test engine was ignited at $12.2 \mathrm{~m}$ above the soil surface; the test area was obscured by blowing dust after engine shutdown, and several minutes were required for the chamber to clear. It seems likely, on the basis of the presence of fine grains on Mars, that the dust cloud caused by the landing would also last several minutes in view of the lower Mars gravity. In addition to the vertical bands in the first picture taken by VL1 , a shadow was cast in the field of view nearly $40 \mathrm{~s}$ after the first picture began. At the time of landing of VL-1 the sun was in the southwest, and winds were probably from the northeast, so a cloud produced by the engines of VL-1 would have passed between the lander and the sun.
The first pictures of Mars also viewed the area of footpad 3 at a time when the dust cloud had settled, and subsequently, pictures were obtained of the region of and around footpad 2. Debris that settled from the dust cloud is found in footpad 3 of both landers and footpad 2 of VL-2. Displaced rocks and fragments occur at distances from the lander that are compatible with the site alteration tests of 1971 . In the tests, rocks located $0.6 \mathrm{~m}$ from the engine axis were moved by the exhaust gases. The largest of these had a mass of $74 \mathrm{~g}$ and was roughly equidimensional with a size of $3.0 \mathrm{~cm}$. The pressure required to move this rock was about $0.7 \mathrm{kN} / \mathrm{m}^{2}$. The rock traveled $1.65 \mathrm{~m}$ from the engine axis, and an initial pressure of about 0.35 $\mathrm{kN} / \mathrm{m}^{2}$ was required to keep it moving at this distance. On Mars a rock of the same dimensions and density would weigh 0.38 as much, so at a radial distance of $0.6 \mathrm{~m}$, loose equidimensional rocks $7.0 \mathrm{~cm}$ across would be moved. At $1.65 \mathrm{~m}$, rock fragments $3.5 \mathrm{~cm}$ across would be moved. Displacements of rocks on Mars are consistent with test results. About $1.6 \mathrm{~m}$ from the VL-1 engine near footpad 3, rocks $7 \times 15 \mathrm{~cm}$ have moved a few tens of centimeters, and at VL-2, rocks $4 \mathrm{~cm}$ across that are $2 \mathrm{~m}$ from the engine have been moved. In one case near the first VL-2 sample site a 4-cm rock lies beside a rimless depression the same size as the rock. Apparently, engine exhausts lifted the rock from its socket.

As in the tests, fragments, grains, and clods propelled by the Viking lander engine exhausts produced small elongate craters. Site alteration tests suggest that velocities of the particles were several tens of meters per second. Morphologies of the craters vary. In general, craters large distances from the engines appear fresh, but those near the engines are partly filled by fines, a situation showing that some aerodynamic sorting occurred during dust cloud formation and the decay of engine thrusts. Near footpad 2 of VL-1, craters both near and at large distances from the engine appear to be fresh. Lack of filling of craters at large distances is probably the result of dispersion of fines over large areas. Although the fresh appearance of craters near footpad 2 may have partly resulted from the transport of fines to the southwest by wind, the impacts of grains and fragments have produced unusually deep craters in the relatively weak drift material, so more fines would be required to subdue them. It may also be that fewer fines were eroded to the left of engine 2 because the grain size of the drift material is so small that it is not readily eroded. In many cases the small grains and fragments that produced the craters lie in or near the craters. Small grains of quartz near $1 \mathrm{~mm}$ in diameter dropped into low-density $\left(600 \mathrm{~kg} / \mathrm{m}^{3}\right)$ lunar nominal soil on earth at velocities of $3.5 \mathrm{~m} / \mathrm{s}$ penetrate several diameters and are not visible after penetration. Larger velocities result in larger penetrations. In view of the presence of small fragments in and by the craters in drift material, it seems unlikely that drift material has a density substantially less than $1300 \mathrm{~kg} / \mathrm{m}^{3}$ because their penetration has been small.

Erosion by the retroengine 2 exhaust gases of both landers produced small shallow craters beneath individual nozzles (viewed through a boom-mounted mirror) and scoured the surface in front of the engines (viewed directly), a crater with a rim of mixed fines and platy to equidimensional fragments of soil and rocks (Figures $2 a$ and $2 c$ ) thus being formed. Fragments imbedded in the rim, which is near $0.5 \mathrm{~m}$ from the VL-1 engine axis, have intermediate diameters near $1 \mathrm{~cm}$ and indicate that erosion has occurred to depths of 1 or $2 \mathrm{~cm}$. The surface to the left of the engine of VL-1 has not been stripped despite the tilt of the spacecraft, which would favor more stripping in this region. Evidence for extensive erosion is found 
on both sides of the VL-2 engine, but it is more extensive to the right front, presumably because of spacecraft tilt. Interpretation is somewhat clouded because a rock $22 \mathrm{~cm}$ across partly occupies the area beneath the engine. In contrast with VL-1 the rim of the erosional crater is not as clearly defined. At distances near $0.5-0.6 \mathrm{~m}$, fragments of rock and soil exposed in the rim are roughly twice as large as those at VL-1, a result suggesting erosion to depths of $2-4 \mathrm{~cm}$. Erosion by the retroengines on Mars is more extensive than that in the lunar nominal soil during site alteration tests and like that of the dune sand. In the lunar nominal soil of the site alteration tests the area below the descent engine was scrubbed, and some soil was removed to a depth of a few millimeters, but no crater was formed, and no signs of separate craters caused by the individual engine nozzles were apparent. Regions of lunar nominal soil prepared at lower density than that of the bulk of the test bed showed no difference in erosion. This indicates that the grain size of the soil is more important than the density in the erosion process. Erosion of the surface in the tests was $0.6 \mathrm{~cm}$ or less at distances of $0.5 \mathrm{~m}$ from the engine center line. For the coarse basalt dune sand, separate craters up to $4.3 \mathrm{~cm}$ deep beneath the individual nozzles were produced, and depths of erosion were near $0.6-1.5 \mathrm{~cm}$ at $0.5 \mathrm{~m}$ from the engine. Thus the response of the Martian surface to the retroengine exhausts is less than that of lunar material and like that of dune sand. Comparison between the relative amounts of erosion between the two landers is at best difficult because the surface did not respond in the exact same manner. The extent of fragments at VL-2 and their large size and concentrations beyond $0.5 \mathrm{~m}$ from the engine suggest that erosion of the surface by VL-2 was greater than it was by VL-1. Such a result could arise from a combination of factors related to landing conditions and the character of the surface. For a short interval of time just prior to thrust termination by VL-2 the increase in thrust subjected the surface to nearly a doubling of the plume impingement pressures and to the viscous shearing stresses exerted along the gas-surface interface. These higher stresses are consistent with a larger amount of erosion of material near retroengine 2 on VL-2 than that on VL-1. The grain size of the surface materials could also affect the amount of erosion. This appears to be the case at VL-1, where erosion of the fine drift material to the left of engine 2 appears to be substantially less than it is to the right, where coarser fragments and clods are present.

\section{Surface Sampler Activities}

Information on the physical properties of the Martian surface materials during the primary mission has been gleaned from normal surface sampler activities during sample acquisitions for the analytical experiments: Biology, Molecular Analysis (gas chromatograph mass spectrometer, GCMS), and Inorganic Chemical Analysis ( $\mathrm{X}$ ray fluorescence spectrometer, XRFS). One sol of the VL-1 mission and 1 sol and part of another sol of the VL-2 mission were allotted to the Physical and Magnetic Properties Investigations, for which sample acquisition procedures were the same as those for the analytical experiments. Surface sampler activities are generalized in Tables 4 and 5, and locations of trenches and rocks are shown in Figures $1 a$ and $1 b$. More detailed data can be found in the summary of surface sampler activities [L. V. Clark et al., 1977]. Typical sample acquisition sequences involve (1) positioning of the sampler boom to the desired azimuth, (2) extension of the collector head to the desired amount, (3) lowering of the collector head to the surface, (4) extension of the collector head into the soil about $0.16 \mathrm{~m}$ with the jaw open to acquire a sample, (5) retraction of the collector head with the jaw closed, and (6) elevation and delivery of the sample normally through $0.2-\mathrm{cm}$ openings in the upper jaw of the collector head. After delivery the remaining coarse fraction is purged or dumped at a preselected position in front of the landers. Included in the normal surface sampler activities are the ejection of a protective shroud early in the mission and the extraction of the restraint (latch) pin of VL-1 on sol 5.

The collector head has a lower jaw $4.45 \mathrm{~cm}$ wide with a serrated tip [Martin Marietta Corporation, 1973b] (see also Figure 12); $10.2 \mathrm{~cm}$ from the serrated tip is a backhoe $6.1 \mathrm{~cm}$ wide and $6.45 \mathrm{~cm}$ high. An upper movable jaw is actuated by a solenoid capable of vibrating the upper jaw at two frequencies: 4.4 and $8.8 \mathrm{~Hz}$. When the jaw is closed, the distance from the base of the lower fixed jaw to the top of the movable jaw is 5.5 $\mathrm{cm}$. The upper surface of the movable jaw has $0.2-\mathrm{cm}$ holes in it to separate the coarse fraction of samples from the fines during delivery of the samples. The collector head assembly is $24.3 \mathrm{~cm}$ long and is attached to a furlable boom. About $21 \mathrm{~cm}$ from the tip of the head the assembly pivots vertically through an arc of $10^{\circ}$. The collector head can be inverted about its longitudinal axis so that material can be sieved through the $0.2-\mathrm{cm}$ holes in the upper jaw.

Surface sampler activities of the two landers were similar but differed in two important ways: (1) the period of intensive operations by VL-2 lasted for 58 sols, whereas that of VL-1 lasted for 41 sols, and (2) rocks were nudged and pushed, and samples were obtained from the newly exposed surfaces beneath the rocks by VL-2. Importantly, endeavors by both spacecraft to collect samples of small rocks and mineral grains in the $0.2-$ to $1.2-\mathrm{cm}$ size range have not been successful. Samples analyzed in this size range by VL-1 have a composition consistent with clods of clayey soil [Baird et al., 1976], and the lumps seen in VL-2 pictures are disaggregated to sizes less than $0.2 \mathrm{~cm}$ during vibration of the collector head.

\section{$V L-1$}

The first samples of Martian soil were acquired from drift material in Sandy Flats, because the profusion of rocks seen elsewhere was absent and fragments propelled by the engine exhausts made impact craters in the drift material there. Samples were subsequently collected from the rocky materials at Rocky Flats. Morphologies of the trenches from the two materials differed significantly. In drift material, surface-samplercommanded azimuths were achieved in all cases, whereas they were not achieved on two occasions in the rocky material. Sample trenches in drift material (Figure 6a) typically had large depths, steep walls, domed and fractured surfaces around the far ends of the trenches produced by extension into the soil, lumpy floors, relatively large, uniform, but lumpy tailings piles produced by the backhoe during retraction, and highly reflective surfaces on disturbed material produced by tamping and rubbing of the surface sampler parts. In contrast, trenches in rocky material (Figure $6 b$ ) had gently sloping lumpy walls, and one trench disrupted the surface material, a chaotic array of fragments several centimeters across thus being produced.

The sample trenches provide quantitative data on the cohesion of the drift material (Figure $6 a$ and Table 4, sols 8, 14, 36, 41 , and 91). Lateral trench walls have arcuate outlines where slope failure has occurred and other outlines where the arcuate pattern outlines material that has not yet collapsed into the trench. Ends of two trenches have collapsed; this produces a steplike mass near the end of the trench and a trench that is longer than the commanded extension by several centimeters. 
TABLE 4. Surface Sampler Activities Related to the Physical Properties Investigation, Viking Lander 1

\begin{tabular}{|c|c|c|c|c|c|c|}
\hline \multirow[b]{2}{*}{ Activity } & \multirow[b]{2}{*}{ Sol } & \multirow[b]{2}{*}{$\begin{array}{l}\text { Local Lander } \\
\quad \text { Time }^{1}\end{array}$} & \multicolumn{3}{|c|}{ Surface Sampler Positions ${ }^{2}$} & \multirow[b]{2}{*}{ Remarks } \\
\hline & & & $\begin{array}{l}\text { Azimuth, } \\
\text { deg }\end{array}$ & $\begin{array}{l}\text { Extension, } \\
\text { inches }\end{array}$ & $\begin{array}{l}\text { Elevation, } \\
\quad \text { deg }\end{array}$ & \\
\hline $\begin{array}{l}\text { Shroud ejection and } \\
\text { retroengine } 2 \text { picture } \\
\text { via boom mirror } 2 \\
\text { (Figures } 1 a \text { and } 2 b \text { ) }\end{array}$ & 02 & $1028: 02$ & 255.4 & 6.0 & 40.1 & $\begin{array}{l}\text { Shroud ejected at } 3.2 \mathrm{~m} / \mathrm{s} \text {, struck surface near footpad } 3 \text { at } 3.6 \mathrm{~m} / \mathrm{s} \text {, producing a shallow crater } 1 \mathrm{~cm} \\
\text { deep and } 9 \mathrm{~cm} \text { in diameter by displacement of rocks and ejection of fine debris, then ricocheted } \\
\text { and came to rest about } 1 \mathrm{~m} \text { from crater (Figure } 2 b \text { ). Picture under retroengine } 2 \text { via boom mirror } 2 \\
\text { showed a small rock and two shallow craters produced by engine exhausts. }\end{array}$ \\
\hline $\begin{array}{l}\text { Restraint (latch) pin } \\
\quad \text { ejection (Figure } 2 b \text { ) }\end{array}$ & 05 & $1042: 47$ & 186.0 & 12.0 & -7.2 & $\begin{array}{l}\text { Restraint (latch) pin }(8.2 \mathrm{~cm} \text { long, } 0.6 \mathrm{~cm} \text { in diameter, and } 11.3 \mathrm{~g} \text { ) fell from } 0.9-1.0 \mathrm{~m} \text { to the surface, } \\
\text { reaching a velocity of } 2.6-2.7 \mathrm{~m} / \mathrm{s} \text {. Pin impacted on an end with small roller bearings, producing a } \\
\text { small circular crater, and then fell over toward the spacecraft, producing an elongate crater. Very } \\
\text { fine grained material was ejected from the craters to distances of } 2.4 \mathrm{~cm} \text { (Figure } 2 b \text { ). }\end{array}$ \\
\hline $\begin{array}{l}\text { Biology I sample } \\
\text { (Sandy Flats, } \\
\text { Figure 1a) }\end{array}$ & 08 & $0705: 10$ & 104.5 & $\begin{array}{l}90.2 \\
96.7 \\
90.2\end{array}$ & 25.0 & $\begin{array}{l}\text { Trenched by extending after surface contact and then retracting; trench about } 45 \mathrm{~cm} \text { long from rim to } \\
\text { rim, } 8.5 \mathrm{~cm} \text { wide from rim to rim, and } 4 \mathrm{~cm} \text { deep; small lumps in and around trench are chiefly } \\
\text { clods; material is very fine grained because materials rubbed and tamped by surface sample parts } \\
\text { are smooth and reflective; small craters on left side of trench produced by wind-driven clods and } \\
\text { debris falling from sampler and boom (Figure } 1 a \text { ). }\end{array}$ \\
\hline $\begin{array}{l}\text { Purge (Biology, } \\
\text { Figure }(a)\end{array}$ & 08 & $0839: 09$ & 110.2 & 10.5 & 37.6 & $\begin{array}{l}\text { Purged material has grain size between } 2.0 \text { and } 5.0 \mathrm{~mm} \text { and may be small clods of surface material } \\
\text { rather than rock or mineral grains; small impact pit produced by purged material (Figure } 1 \mathrm{a} \text { ). }\end{array}$ \\
\hline \multirow[t]{2}{*}{$\begin{array}{l}\text { GCMS I sample (Sandy } \\
\text { Flats, Figures l } a \\
\text { and } 6 a \text { ) }\end{array}$} & 08 & $0903: 32$ & 104.5 & $\begin{array}{l}90.2 \\
96.7 \\
90.2\end{array}$ & 25.6 & \multirow[t]{2}{*}{$\begin{array}{l}\text { Trenched by extending after contact and then retracting with identical commands as above. No } \\
\text { pictures of the trench were obtained, engineering data indicate that amount of sample delivered } \\
\text { was unusually small after two attempts and surface domed at far end of trench to } 10 \mathrm{~cm} \text { along } \\
\text { trench axis and } 7 \mathrm{~cm} \text { in lateral directions from rim (Figure } 6 \mathrm{~b} \text { ). }\end{array}$} \\
\hline & 08 & $0931: 56$ & 104.5 & $\begin{array}{l}90.2 \\
96.7 \\
90.2\end{array}$ & 25.6 & \\
\hline $\begin{array}{l}\text { Purge (GCMS } 1 \text {, } \\
\quad \text { Figure } 1 a \text { ) }\end{array}$ & 08 & $0953: 25$ & 110.2 & 9.7 & 37.6 & Available data suggest no purged material. \\
\hline \multirow[t]{2}{*}{$\begin{array}{l}\text { XRFS } 1 \text { sample } \\
\text { (Sandy Flats, } \\
\text { Figures l } a \text { and } 6 a \text { ) }\end{array}$} & 08 & $1045: 55$ & 104.5 & $\begin{array}{r}94.1 \\
100.7 \\
94.1\end{array}$ & 24.3 & \multirow[t]{2}{*}{$\begin{array}{l}\text { Trenched by extending after surface contact then retracting; trench and tailings about } 70 \mathrm{~cm} \text { long, } \\
\text { far end about } 10 \mathrm{~cm} \text { across, and trench about } 4-6 \mathrm{~cm} \text { deep. Surface domed to about } 10 \mathrm{~cm} \text { from } \\
\text { rim; measurements and images indicate that wall at end of trench collapsed and incipient failure } \\
\text { occurred on left side of trench (Figures } 1 a \text { and } 6 a \text { ). }\end{array}$} \\
\hline & 08 & $1132: 55$ & 104.5 & $\begin{array}{r}94.1 \\
100.7 \\
94.1\end{array}$ & 25.0 & \\
\hline \multirow[t]{2}{*}{$\begin{array}{l}\text { Purges (XRFS } 1 \text {, } \\
\text { Figure } 1 a)\end{array}$} & 08 & $1110: 18$ & 110.2 & 11.5 & 37.6 & \multirow[t]{2}{*}{$\begin{array}{l}\text { Purged material has grain size between } 2.0 \text { and } 5.0 \mathrm{~mm} \text { and may be small clods of surface material } \\
\text { rather than rock or mineral grains; small impact pits produced by purged material (Figure } 1 a \text { ). }\end{array}$} \\
\hline & 08 & $1157: 18$ & 110.2 & 11.5 & 37.6 & \\
\hline $\begin{array}{l}\text { GCMS } 2 \text { sample } \\
\text { (Sandy Flats, } \\
\text { Figures } 1 a \text { and } 6 a \text { ) }\end{array}$ & 14 & $0635: 42$ & 107.7 & $\begin{array}{l}90.2 \\
96.7 \\
90.2\end{array}$ & 25.6 & $\begin{array}{l}\text { Trenched by extending after surface contact then retracting; trench and tailings about } 47 \mathrm{~cm} \text { long, } \\
\text { trench is } 7 \mathrm{~cm} \text { wide at far end and } 2.3 \mathrm{~cm} \text { deep, doming to about } 7 \mathrm{~cm} \text { from rim; septum between } \\
\text { XRFS } 1 \text { trench and this trench was displaced toward XRFS trench during sampling. Sample was } \\
\text { not analyzed by GCMS (Figures } 1 a \text { and } 6 a \text { ). }\end{array}$ \\
\hline
\end{tabular}


TABLE 4. (Continued)

\begin{tabular}{|c|c|c|c|c|c|c|}
\hline \multirow[b]{2}{*}{ Activity } & \multirow[b]{2}{*}{ Sol } & \multirow[b]{2}{*}{$\begin{array}{l}\text { Local Lander } \\
\quad \text { Time }^{1}\end{array}$} & \multicolumn{3}{|c|}{ Surface Sampler Positions ${ }^{2}$} & \multirow[b]{2}{*}{ Remarks } \\
\hline & & & $\begin{array}{c}\text { Azimulh, } \\
\text { deg }\end{array}$ & $\begin{array}{l}\text { Extension, } \\
\text { inches }\end{array}$ & $\begin{array}{c}\text { Elevation, } \\
\text { deg }\end{array}$ & \\
\hline Purge (GCMS 2) & 22 & $1227: 49$ & 87.5 & 9.9 & 37.6 & Purged material on surface obscured by lander body. \\
\hline $\begin{array}{l}\text { GCMS } 3 \text { sample } \\
\text { (Rocky Flats, } \\
\text { Figures } 1 a \text { and } 6 b \text { ) }\end{array}$ & 31 & $1051: 02$ & 204.9 & $\begin{array}{l}70.2 \\
76.5 \\
64.4\end{array}$ & 30.0 & $\begin{array}{l}\text { Trenched by extending after surface contact then retracting; trench and tailing about } 42 \mathrm{~cm} \text { long, } \\
\text { far end about } 7.6 \mathrm{~cm} \text { across, and trench } 3-5 \mathrm{~cm} \text { deep (Figures } 1 a \text { and } 6 b \text { ). }\end{array}$ \\
\hline $\begin{array}{l}\text { Purge (GCMS 3, } \\
\text { Figure } 1 a \text { ) }\end{array}$ & 31 & $1118: 02$ & 194.8 & 42.0 & 37.6 & $\begin{array}{l}\text { Purged material has grain size a few millimeters across and may be small clods; no impact pits (Figure } \\
\text { la). }\end{array}$ \\
\hline \multirow[t]{2}{*}{$\begin{array}{l}\text { XRFS } 2 \text { sample } \\
\text { (Rocky Flats, } \\
\text { Figures la and } 6 b \text { ) }\end{array}$} & 34 & $1019: 21$ & 203.6 & $\begin{array}{l}62.0 \\
67.5 \\
56.2\end{array}$ & 33.2 & \multirow{2}{*}{$\begin{array}{l}\text { Trenched by extending after surface contact and then retracting; trench and tailings about } 33 \mathrm{~cm} \text { long } \\
\text { and } 5-7 \mathrm{~cm} \text { wide; disrupted region at } 3 \text { ar end is } 19 \mathrm{~cm} \text { across; first pass by surface sampler did not } \\
\text { attain the commanded extension at } 68.6 \text { inches, an indication that forces near } 210 \mathrm{~N} \text { were applied } \\
\text { lo surface by surface sampler; second pass by surface sampler achieved the commanded extension } \\
\text { (Figures } 1 a \text { and } 6 b \text { ). }\end{array}$} \\
\hline & 34 & $1119: 21$ & & $\begin{array}{l}62.0 \\
68.6 \\
56.2\end{array}$ & 33.8 & \\
\hline \multirow{2}{*}{$\begin{array}{l}\text { Purges (XRFS 2, } \\
\text { Figure } 1 a)\end{array}$} & 34 & $1041: 45$ & 194.8 & 42.0 & 37.6 & Purged materıal a few millimeters across (Figure $1 a$ ). \\
\hline & 34 & $1141: 45$ & 194.8 & 42.0 & 37.6 & \\
\hline $\begin{array}{l}\text { Biology } 2 \text { samples } \\
\text { (Sandy Flats, } \\
\text { Figures } 1 a \text { and } 6 a \text { ) }\end{array}$ & 36 & $1121: 02$ & 104.5 & $\begin{array}{l}78.3 \\
84.9 \\
72.8\end{array}$ & 27.5 & $\begin{array}{l}\text { Trenched by extending after surface contact and then retracting; trench and tailings about } 50 \mathrm{~cm} \\
1 \text { long, } 6-7 \mathrm{~cm} \text { wide, and } 4-5 \mathrm{~cm} \text { deep; trench transects tailings of previous sol } 8 \text { trenches (Figures } 1 a \\
\text { and } 6 a \text { ). }\end{array}$ \\
\hline $\begin{array}{l}\text { Purge (Biology } 2 . \\
\text { Figure } 1 a)\end{array}$ & 36 & $1322: 40$ & 194.8 & 42.0 & 37.6 & Purged material a few millimeters across (Figure $1 a$ ). \\
\hline \multirow[t]{2}{*}{$\begin{array}{l}\text { XRFS } 3 \text { sample } \\
\text { (Rocky Flats, } \\
\text { Figure la) }\end{array}$} & 40 & $1038: 39$ & 204.9 & $\begin{array}{l}74.6 \\
81.2 \\
69.1\end{array}$ & 28.8 & $\begin{array}{l}\text { Trenched by extending after surface contact and then retracting: trench extends } 8-9 \mathrm{~cm} \text { beyond } \\
\text { GCMS } 3 \text { trench along same azimuth. Clod and rock fragments } 2-4 \mathrm{~cm} \text { across. First pass achieved } \\
\text { commanded extension, second pass did not achieve commanded extension, an indication that forces } \\
\text { near } 210 \mathrm{~N} \text { were applied by surface sampler (Figure } 1 a \text { ). }\end{array}$ \\
\hline & 40 & $1218: 39$ & 204.9 & $\begin{array}{l}74.6 \\
80.9 \\
69.1\end{array}$ & 28.8 & \\
\hline $\begin{array}{l}\text { Picture of footpad } 2 \\
\text { temperature sensor } \\
\text { via boom mirror } 1\end{array}$ & 40 & $1106: 02$ & 125.4 & NA & 35.1 & $\begin{array}{l}\text { Picture included part of temperature sensor housing; a subsequent picture taken during extended } \\
\text { mission shows that temperature sensing elements are buried but entire housing is not. }\end{array}$ \\
\hline
\end{tabular}




\begin{tabular}{|c|c|c|c|c|c|c|}
\hline \multirow[t]{2}{*}{$\begin{array}{l}\text { Purge of fines (XRFS } \\
\text { 3) }\end{array}$} & 40 & $1042: 29$ & 204.9 & 69.1 & 7.9 & Purge of fines cannot be recognized by using visual inspection of pictures. \\
\hline & 40 & $1222: 29$ & 204.9 & 69.1 & 7.9 & \\
\hline \multirow{2}{*}{$\begin{array}{l}\text { Purge of coarse material } \\
\text { (XRFS 3, Figure } 1 a)\end{array}$} & 40 & $1114: 18$ & 189.8 & 42.0 & 37.6 & Purge. \\
\hline & 40 & $1254: 18$ & 189.8 & 42.0 & 37.6 & \\
\hline $\begin{array}{l}\text { Physical Properties } 1 \\
\text { sample temperatures } \\
\text { (Sandy Flats, } \\
\text { Figures } 1 a \text { and } 6 a \text { ) }\end{array}$ & 41 & $1537: 45$ & 101.4 & $\begin{array}{l}78.3 \\
84.9 \\
72.8\end{array}$ & 27.5 & $\begin{array}{l}\text { Trenched by extending after surface contact and then retracting; trench and tailings about } 55 \mathrm{~cm} \\
\text { long, } 6 \mathrm{~cm} \text { wide, and } 6 \mathrm{~cm} \text { deep; trench is unusually narrow, and visual picture differencing } \\
\text { shows that septum between this trench and the Biology } 3 \text { trench moved toward Physical Properties } \\
\text { trench rather than toward the previously formed Biology } 3 \text { trench. Surface sampler collector head } \\
\text { temperatures were } 272^{\circ} \mathrm{K} \text { at extension and } 269^{\circ} \mathrm{K} \text { in the surface material at } 10.7 \text { and } 11 \mathrm{~min} \\
\text { after extension (Figures } \operatorname{la} \text { and } 6 a \text { ). }\end{array}$ \\
\hline $\begin{array}{l}\text { Physical Properties } \\
\text { magnification mirror } \\
\text { image of front porch }\end{array}$ & 41 & $1558: 04$ & 4.2 & 24.7 & 0.3 & Front porch picture. \\
\hline $\begin{array}{l}\text { Purge of fines on lander } \\
\text { grid (Physical Proper- } \\
\text { ties 1, Figure 7) }\end{array}$ & 41 & $1603: 42$ & 4.2 & 24.7 & 3.5 & $\begin{array}{l}\text { Purge of fines on lander grid produced more or less conical mounds. Pictures taken with a sun } \\
\text { elevation angle of } 38^{\circ} \text { show that slopes of mound are shadowed, so angle of repose is }>38^{\circ} \\
\text { (Figure 7). }\end{array}$ \\
\hline $\begin{array}{l}\text { Purge of coarse material } \\
\text { (Physical Properties 1, } \\
\text { Figure } 1 a \text { ) }\end{array}$ & 41 & $1617: 41$ & 189.8 & 42.0 & 37.6 & Purge (Figure $1 a$ ). \\
\hline $\begin{array}{l}\text { Biology } 3 \text { sample } \\
\text { (Sandy Flats, } \\
\text { Figures } 1 a \text { and } 6 a \text { ) }\end{array}$ & 91 & $0711: 02$ & 107.7 & $\begin{array}{l}78.3 \\
84.9 \\
72.8\end{array}$ & 28.8 & $\begin{array}{l}\text { Trenched by extending after surface contact and then retracting; trench and tailings about } 50 \mathrm{~cm} \\
\text { long, } 6 \mathrm{~cm} \text { wide, and } 4-5 \mathrm{~cm} \text { deep; trench transects tailing of previous sol } 14 \text { GCMS } 2 \text { trench } \\
\text { (Figures } \mathrm{la} \text { and } 6 a \text { ). }\end{array}$ \\
\hline $\begin{array}{l}\text { Purge (Biology } 3, \\
\text { Figure } 1 a \text { ) }\end{array}$ & 91 & $0844: 41$ & 189.8 & 42.0 & 37.6 & Purge (Figure $l a$ ). \\
\hline
\end{tabular}

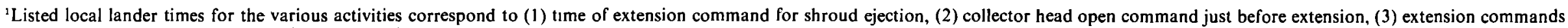
for nudges and pushes, and (4) vibration commands for purges.

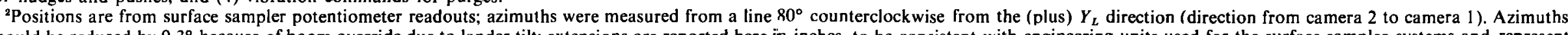

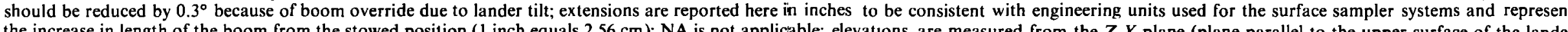

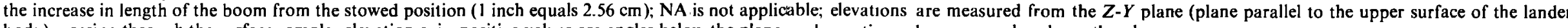
body), passing through the surface sampler elevation axis; positive values are angles below the plane, and negative values are angles above the plane. 
TABLE 5. Surface Sampler Activities Related to the Physical Properties Investigation, Viking Lander 2

\begin{tabular}{|c|c|c|c|c|c|c|}
\hline \multirow[b]{2}{*}{ Activity } & \multirow[b]{2}{*}{ Sol } & \multirow[b]{2}{*}{$\begin{array}{l}\text { Local Lander } \\
\text { TIme }^{1}\end{array}$} & \multicolumn{3}{|c|}{ Surface Sampler Positıons ${ }^{2}$} & \multirow[b]{2}{*}{ Remarks } \\
\hline & & & $\begin{array}{c}\text { Azimuth, } \\
\text { deg }\end{array}$ & $\begin{array}{l}\text { Extension, } \\
\text { inches }\end{array}$ & $\begin{array}{l}\text { Elevation, } \\
\text { deg }\end{array}$ & \\
\hline $\begin{array}{l}\text { Shroud ejection (see } \\
\text { Figure } 1 b \text { ) }\end{array}$ & 01 & $1052: 02$ & 255.4 & 10.2 & 38.9 & $\begin{array}{l}\text { Shroud ejected at } 3.2 \mathrm{~m} / \mathrm{s} \text {, struck a rock near footpad } 3 \text { at } 3.7 \mathrm{~m} / \mathrm{s} \text {, ricocheted from rock, impacting } \\
\text { surface } 0.6 \mathrm{~m} \text { beyond rock, and came to rest } 1.1 \mathrm{~m} \text { beyond rock (Figure } 1 \mathrm{~b} \text { ); rock near footpad } 3 \\
\text { moved a small amount as a result of the impact. }\end{array}$ \\
\hline $\begin{array}{l}\text { Biology } 1 \text { sample } \\
\text { (Beta, see Figures } 1 b \\
\text { and } 8 a \text { ) }\end{array}$ & 08 & $1610: 20$ & 124.7 & $\begin{array}{l}85.2 \\
91.7 \\
79.6\end{array}$ & $\begin{array}{l}23.1 \\
\cdots\end{array}$ & $\begin{array}{l}\text { Trenched by extending after surface contact and then retracting; trench and tailings about } 40 \mathrm{~cm} \\
\text { long from rim to rim and } 7.6 \mathrm{~cm} \text { wide from rim to rim; sample delivered to Biology; coarse fraction } \\
\text { purged to XRFS funnel, but no sample was received (Figures } 1 b \text { and } 8 a \text { ). Small lumps in and } \\
\text { around trench are probably chiefly clods. }\end{array}$ \\
\hline $\begin{array}{l}\text { GCMS } 1 \text { sample } \\
\text { (Bonneville, see } \\
\text { Figures } 1 b, 8 b \text {, and 9) }\end{array}$ & 21 & $1010: 19$ & 216.3 & $\begin{array}{l}93.6 \\
88.8 \\
97.3 \\
91.2\end{array}$ & $\begin{array}{l}30.0 \\
\cdots \\
\cdots\end{array}$ & $\begin{array}{l}\text { Trenched by retracting after surface contact, then extending, and finally by retracting; trench about } \\
25 \mathrm{~cm} \text { long, } 5.6 \mathrm{~cm} \text { wide at far tip, and } 7.3 \mathrm{~cm} \text { wide near tip. Collector head tunneled beneath } \\
\text { crust, doming surface and crust near far tip. Platy fragment of crust near } 7 \mathrm{~cm} \text { across and } 1 \mathrm{~cm} \\
\text { thick was moved by backhoe (Figures } 1 a \text { and } 8 b \text { ). }\end{array}$ \\
\hline $\begin{array}{l}\text { Purge (GCMS 1, } \\
\text { Figure } 1 b)\end{array}$ & 21 & $1053: 46$ & 190.4 & 39.9 & 36.3 & $\begin{array}{l}\text { Purged material greater than } 2.0 \mathrm{~mm} \text {; a fragment } 2.7 \mathrm{~cm} \text { across and additional finer grains or clods } \\
2 \mathrm{~mm} \text { and larger (Figure } 2 b \text { ). }\end{array}$ \\
\hline $\begin{array}{l}\text { Biology } 2 \text { sample } \\
\text { (Beta, see Figure } 1 b)\end{array}$ & 28 & $1610: 31$ & 126.0 & $\begin{array}{l}85.2 \\
91.7 \\
79.6\end{array}$ & $\begin{array}{r}23.1 \\
\cdots \\
\cdots\end{array}$ & $\begin{array}{l}\text { Trenched by extending after surface contact and then retracting. Trench and tailings about } 40 \mathrm{~cm} \\
\text { long and } 7.6 \mathrm{~cm} \text { wide: sample delivered to Biology (Figure } 1 \mathrm{~b} \text { ). }\end{array}$ \\
\hline $\begin{array}{l}\text { Purge (Biology } 2, \\
\text { Figure } 1 b)\end{array}$ & 28 & $1744: 46$ & 190.4 & 39.9 & 36.3 & Purged material should be greater than $2.0 \mathrm{~mm}$; no evidence for purged coarse particles (Figure $1 \mathrm{~b}$ ). \\
\hline \multirow[t]{2}{*}{$\begin{array}{l}\text { XRFS } 1 \text { sample } \\
\text { (Bonneville, Figures } \\
1 b, 8 b, \text { and } 9 \text { ) }\end{array}$} & 29 & $1339: 56$ & 217.5 & $\begin{array}{l}93.0 \\
99.4 \\
90.9\end{array}$ & $\begin{array}{r}29.4 \\
\cdots \\
\cdots\end{array}$ & \multirow{2}{*}{$\begin{array}{l}\text { Trenched by extending after surface contact and then retracting; first acquisition extension lifted rock } \\
\text { at far end of trench about } 0.4 \mathrm{~cm} \text {; large platy fragments of crust in and around trench and fine- } \\
\text { grained material in debris pile at tip (Figures } 1 b \text { and } 8 b \text { ); trench and tailings } 28 \mathrm{~cm} \text { long, } 7.7 \mathrm{~cm} \\
\text { wide at far end, and } 9.4 \mathrm{~cm} \text { wide at near end; note that material at far end has spread laterally to } \\
\text { trench azimuth because of rock; rectangular fragment about } 3 \mathrm{~cm} \text { on an edge and } 1 \mathrm{~cm} \text { thick. }\end{array}$} \\
\hline & 30 & $1039: 56$ & 217.5 & $\begin{array}{l}93.0 \\
99.4 \\
90.9\end{array}$ & $\begin{array}{c}30.0 \\
\cdots \\
\cdots\end{array}$ & \\
\hline \multirow[t]{2}{*}{$\begin{array}{l}\text { Purge (XRFS 1, } \\
\text { Figure } 1 b)\end{array}$} & 29 & $1405: 45$ & 190.4 & 39.9 & 36.3 & $\begin{array}{l}\text { Purged material greater than } 2.0 \mathrm{~min} \text {; a large fragment has been displaced, and purged material } 5 \mathrm{~mm} \\
\text { and smaller has been added (Figure } 1 b \text { ). }\end{array}$ \\
\hline & 30 & $1105: 45$ & 190.4 & 39.9 & 36.3 & \\
\hline $\begin{array}{l}\text { Rock } 1 \text { nudge (initial } \\
\text { computer load (ICL), } \\
\text { see Figure } 1 b \text { ) }\end{array}$ & 30 & $1129: 34$ & 186.4 & $\begin{array}{l}75.4 \\
78.6\end{array}$ & $\begin{array}{l}33.2 \\
30.6\end{array}$ & $\begin{array}{l}\text { Nudged by elevating after surface contact, then extending, and finally retracting; surface sampler did } \\
\text { not achieve commanded extension, which was } 83.1 \text { inches; rock did not move (Figure } 1 b \text { ); force } \\
\text { on rock was near } 210 \mathrm{~N} \text { (Figure } 1 b \text { ). }\end{array}$ \\
\hline $\begin{array}{l}\text { Rock } 3 \text { push } \\
\text { (Mr. Badger, see } \\
\text { Figures } 1 b \text { and } 10 \text { ) }\end{array}$ & 34 & $1039: 40$ & 201.1 & $\begin{array}{l}84.4 \\
96.5 \\
82.0\end{array}$ & $\begin{array}{l}30.6 \\
30.0 \\
\cdots\end{array}$ & $\begin{array}{l}\text { Pushed by elevating after surface contact, then extending, and finally retracting; rock was pushed } \\
\text { about } 10 \mathrm{~cm} \text { away from lander, rotated about } 60^{\circ} \text { or } 70^{\circ} \text { counterclock wise about vertical axis, and } \\
\text { tilted near } 45^{\circ} \text { about a horizontal axis. Collector head went beneath rock which leaned on collector } \\
\text { head, deflecting it to the right; this forced the excavation of trench in front of rock (Figures } 1 b \text { and } 10 \text { ). }\end{array}$ \\
\hline
\end{tabular}




\section{GCMS 2 sample}

37

$1614: 48$

see Figures $1 b$ and 10

Figure $1 b$ )

Rock 6 nudge (Bonneville, see Figure $(b)$

$1010: 28$

217.5

Rock 7 nudge (Notch, see Figure $1 b$ )

XRFS 2 sample

(Beta, see Figure $1 b$ )

93.0
84.1
Pushed by elevating after surface contact, then extending, and finally retracting; rock was pushed an additional 12 or $15 \mathrm{~cm}$ away from lander with little rotation. Commanded extensions compared with measurements of rock indicate that rock tilted backward and then forward to its present position (Figures $1 b$ and 10 ).

28.8 Trenched by retraction after surface contact to clear debris away, elevating, extending, and deeleva... ting to touchdown, extending for sample acquisition, and then retracting. Trench about $30 \mathrm{~cm}$ $20.5,30.0$ long and $10 \mathrm{~cm}$ wide (Figures $1 b$ and 10 ). Sample was delivered to GCMS from first acquisition, 29.4

\section{$20.5,30.6$}

Purged material should be greater than $2.0 \mathrm{~mm}$; no evidence for purged material (Figure $1 b$ ).

25.6, 26.2 Nudged by elevating after surface contact and then extending; reversal of elevations was related to ... boom sag and overtravel; rock rotated about a nearly horizontal axis, and points on front surface ... of rock were displaced upward about $0.4 \mathrm{~cm}$ during nudge (Figure $1 b$ ); rock fell back again after collector head retraction, pushing materials from trench rim into trench.

23.1, 22.4 Nudged by elevating after surface contact and then extending; rock rotated in horizontal plane about $\ldots$ an axis on right side of rock; left edge of rock was displaced about $3.8 \mathrm{~cm}$ (Figure $1 \mathrm{~b}$ ).

Final trench about $30 \mathrm{~cm}$ long and $8 \mathrm{~cm}$ wide (Figure $\mathrm{l} b$ ). Sampled to collect rocks, but little or no sample was received. Some fragments at surface may be rocks, but most are clods of soil.

\section{7}

$\cdots$ 
Surface Sampler Positions ${ }^{2}$

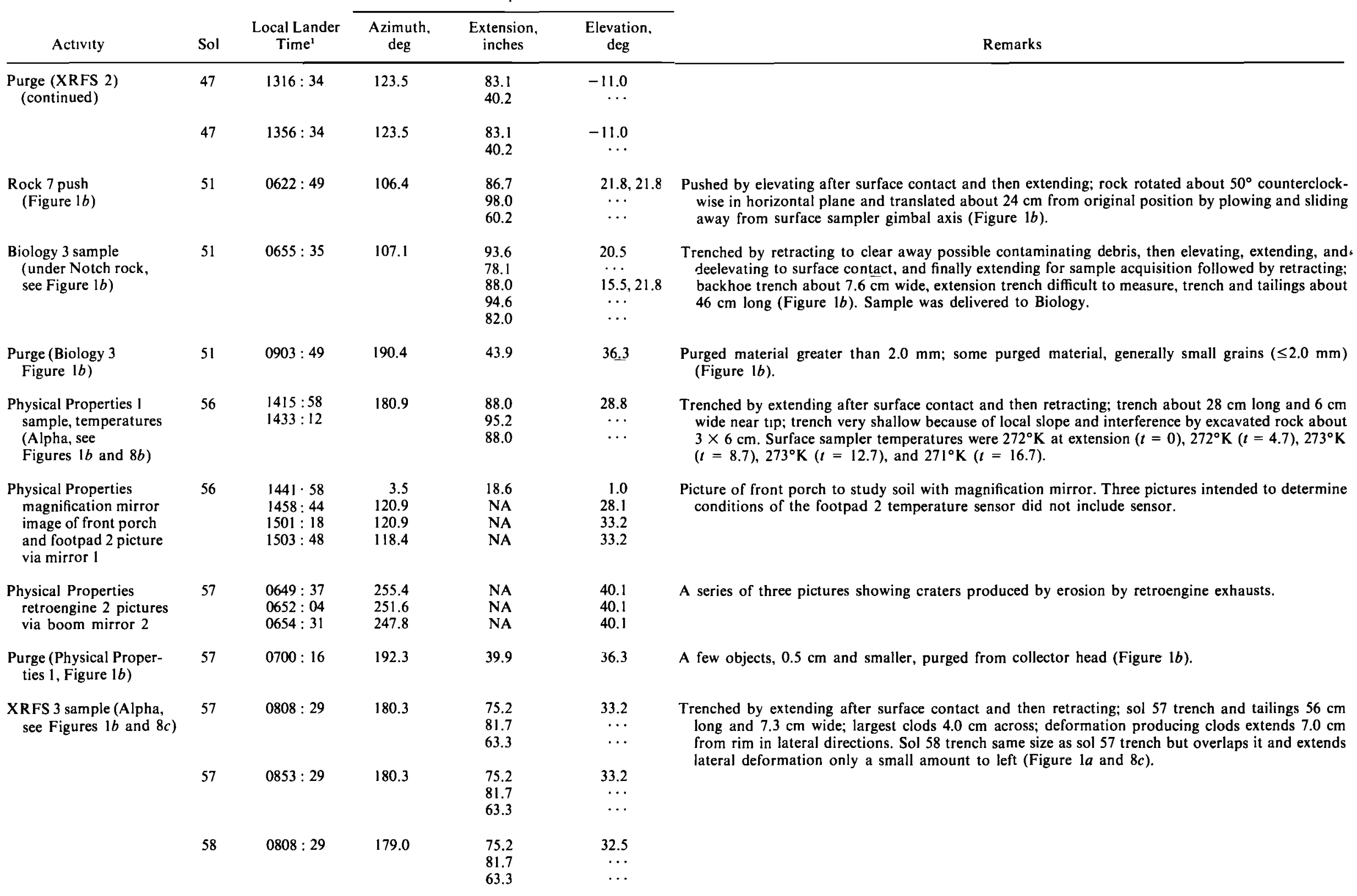


These observations suggest that the trench slopes range from instability to marginal stability. The behavior of the ridge between the sol 36 and the sol 40 trench during sampling lends further evidence for marginal stability. In contrast with the other trenches for which the ridge between them was displaced toward the previously formed trench during the later insertion of the surface sampler, the ridge between the sol 41 and the sol 36 Biology trench was displaced away from the previously formed trench toward the later trench, presumably after retraction. The end result is an unusually narrow trench (Figure $6 a$ ). Slopes of the upper trench walls are commonly greater than $60^{\circ}$, and locally they are $80^{\circ}$, and trench depths are as large as 5-6 cm. Slope stability factors for soils possessing both friction and cohesion for slope angles greater than $60^{\circ}$ and angles of internal friction between zero and $\approx 30^{\circ}$ are $[S$ cott , 1963]

$$
4<\rho g h / C \approx<15
$$

For densities $\rho$ in the range of $1000-1800 \mathrm{~kg} / \mathrm{m}^{3}$, Mars gravity $g$, and trench depths $h$ of $5-6 \mathrm{~cm}$, the cohesion $C$ of the drift material comes out to be in the range of $10-10^{2} \mathrm{~N} / \mathrm{m}^{2}$.

Insertion of the surface sampler into the soil causes the surface around it to be deformed upward. Deformation of the surface around the trenches extends to one trench width $(\approx 7.0$ $\mathrm{cm}$ ) in lateral directions and at least $10 \mathrm{~cm}$ along the trench azimuth from the far rim and represents failure by general shear which in turn implies internal friction.

The highly reflective surfaces produced by tamping and rubbing by the surface sampler show that drift material is fine grained and probably silt size or smaller. In preflight tests in sand, lunar nominal soil, and montmorillonite, only the finergrained simulants became reflective when they were tamped and rubbed by the sampler. Lumps seen in and around the trench are weakly cohesive clods.

The $\mathrm{X}$ ray fluorescence spectrometer is capable of estimating the densities of the material in the analysis chamber [B. $C$. Clark et al., 1976]. These authors find that the density of the delivered sample of drift material is $1100 \pm 150 \mathrm{~kg} / \mathrm{m}^{3}$. This density is consistent with the relatively low densities implied by the penetration by footpad 2. It is possible that in situ densities could be either slightly larger or smaller than the disturbed density of the delivered sample. Chemically, samples of drift material are best interpreted as weathering products of mafic igneous rock, possibly clay minerals [Baird et al., 1976].

Trenches in rocky material do not lend themselves to slope stability analysis. The contrasting appearance of the trenches combined with the fact that the surface sampler failed to reach the commanded extensions on some occasions but not on others can be interpreted to result from materials with signifcantly variable cohesion which may be locally large. This is discussed later.

Sampling at Rocky Flats (Table 4, sols 34 and 40) for Inorganic Chemical Analysis was intended to collect rocks (Figure 6b). Initially, small knobs and lumps there were interpreted to be rocks. Analysis of the coarse fraction delivered for Inorganic Chemical Analysis revealed that the composition of the coarse fraction was similar to that of drift material, although the sulfur content was higher [B. C. Clark et al., 1976]. The bulk density of the coarse fraction delivered was a mere $600 \pm 100 \mathrm{~kg} / \mathrm{m}^{3}$ and is consistent with soil clods having bulk densities of $1200 \mathrm{~kg} / \mathrm{m}^{3}$ and a void volume between the soil clods of 50\% [B. C. Clark et al., 1976]. Thus it appears that the material that arrested footpad 3 may need only be cohesive and not dense, as is implied by the footpad analysis (see Figures 4 and 5). 

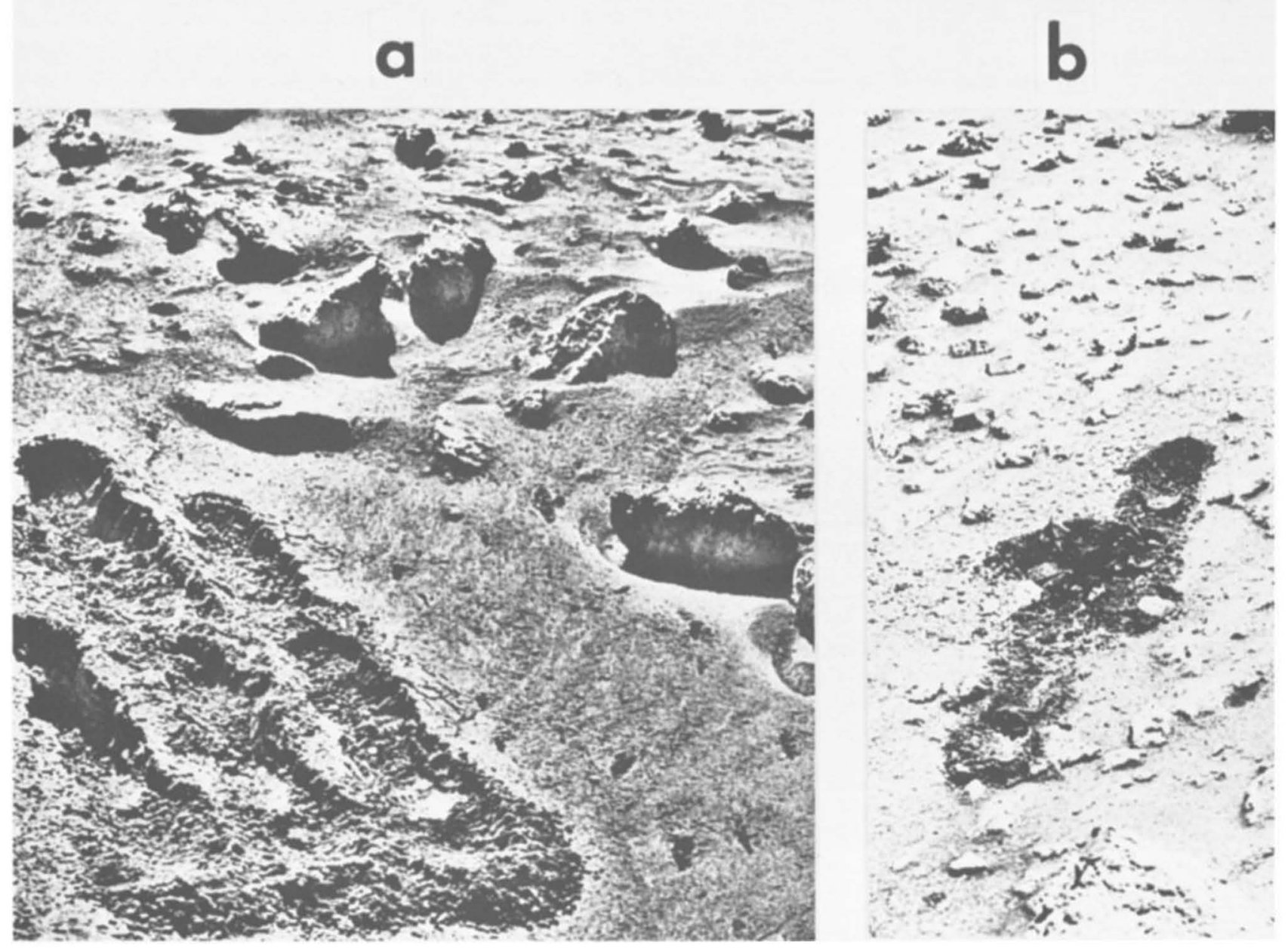

Fig. 6. Trenches excavated by VL-1 during the primary mission. (a) Trenches in drift material of Sandy Flats (see Figure 1a): the upper two trenches were excavated on sols 8 (upper left, XRFS 1) and 14 (upper right, GCMS 2). Actually, five acquisition strokes were made along the same azimuth on sol 8. The lower three trenches were excavated on sols 41 (lower left, Physical Properties), 36 (lower center, Biology 2), and 91 (lower right, Biology 3). Note that the left edge of the sol 8 trench at left center has slumped, the sol 14 trench to the right is unusually shallow, and the sol 41 trench at the lower left is unusually narrow; also note the steplike structure of the sol 41 trench where the end of the trench has collapsed. Local highly refiective surfaces in disturbed material were produced by tamping and rubbing of the surface sampler and show that the drift material is very fine grained. Dimensions of the trenches are given in Table 4. Note the deffation hollows in front of the rocks to the right and the wind tails behind the rocks in the background. (VL-1 camera 1, frame B180; sol 91, 0904:59 LLT; sun elevation, $47.2^{\circ}$; sun is to the right.) (b) Rocky material of Rocky Flats (see Figure la): the trench at right center was excavated on sol 31 (GCMS 2); the trench extending to the lower left was excavated on sol 34 (XRFS 2). Note the disrupted material with fragments about $4 \mathrm{~cm}$ across at the far end of the sol $34 \mathrm{trench}$. Dimensions of the trenches are given in Table 4. (VL-1 camera 1, frame B030; sol 34, 1255:00 LLT; sun elevation, 81.6 ${ }^{\circ}$.)

After normal acquisitions, small amounts of coarse frag. ments $0.2-0.5 \mathrm{~cm}$ across were purged in the field of view. Although these coarse particles were initially thought to be rock fragments, the results of the Inorganic Chemical Analysis strongly suggest that they are clods with unusually large cohesion.

Drift materials were deposited on the grid of the upper lander body through the collector head sieve; thus a conical pile was produced, and debris was scattered (see Table 4, sol 41). Most of the grid was obscured, but with time, winds have removed some of the scattered debris. The angle of repose of the material is near $39^{\circ}$ as shown by the dark shadow cast on the right side of the pile by the sun, which was at an elevation of $38.7^{\circ}$ (Figure 7 ). This indicates that the angle of internal friction of drift material in a loose state [Terzaghi, 1943] is near $39^{\circ}$.

\section{$V L-2$}

Sampling operations by VL-2 (Table 5) were substantially affected by the profusion of rocks, and considerable effort was expended, first dodging and later pushing and nudging them. Three basic types of trenches (Figure 8) were produced during sampling activities by VL-2: (1) trenches with knobby raised rims, (2) trenches with rims of thin platy fragments mixed with finer debris, and (3) trenches that produced blocky fragments. In the first type the regular knobby raised rims are similar to trenches produced in coarse sand and rock fragments during tests on earth (Figure $8 a$ and Table 5, sol 8). The rims com- 
posed of lumps a fraction of a centimeter across are uniform in appearance, and no large clods or cohesive blocks are present, so the lumps, while they are cohesive themselves, do not have much interlump cohesion. Teeth marks made during retraction of the collector head tip and backhoe are poorly preserved as they would be in sand, but no tamping or smoothing has occurred.

In the second kind of trench the presence of platy objects is striking (Figure $8 b$ and Table 5, sols 21 and 29). Presample pictures suggest that the sampled area was a cohesive fractured material in which the small knobby fragments and fines seen elsewhere had been removed by erosion (Figure 9a). Prior to acquisition of the first sample at this site a picture of the backhoe during touchdown was obtained (Figure $9 b$ ). The contact switch stopped the sampler when the backhoe had penetrated the fractured material about $1 \mathrm{~cm}$. The force required to cause this penetration is not great, about $10 \mathrm{~N}$, and the penetration is about the same as the sampler achieves in a medium-dense fine-grained normal terrestrial soil like lunar nominal. Trenching during both extension and retraction shows that this is a thin weak crust. In the first trench formed, the surface sampler extended into the material, doming and fracturing the surface. After retraction, pictures revealed a cavity overlain by a thin arch of the domed surface at the far end. During retraction of the backhoe a plate of the crust was pulled backward (Figure $8 b$ ). Subsequent trenches left a residue of the platy crust intermixed with a pile of fines.

The third type of trench has thick angular clods of soil to distances of $7 \mathrm{~cm}$ or so from the edge of the trench (Figure $8 \mathrm{c}$ and Table 5, sol 57). Sizes of the upper surfaces of the clods are the same as those of undisturbed blocks of soil partly etched out by erosion in adjacent areas. The principal difference between this type of trench and the previous one is that the angular clods are much thicker than the plates, and they may extend well below the surface.

Although large rocks are abundant, attempts to collect small rocks $0.2-1.2 \mathrm{~cm}$ across from the Beta and Alpha sites (Figure $1 b$ ) have been unsuccessful. After eight attempts to collect 'rocks,' no sample was found to be present in the XRFS chamber (Table 5, sols 46, 47, 57, and 58). Examination of the purge site after a sample acquisition at Alpha (Table 5, sol 28) also gave no evidence for purged coarse material. Endeavors to build a rock pile during the extended mission by sifting samples with the collector head sieve from the same general area of the Beta site area have yielded two or three centimetersize rocks after 11 tries. Thus it appears that the smaller lumps are chiefly weakly cohesive clods of material with grains finer than $0.2 \mathrm{~cm}$ etched out by weathering, wind, and possibly engine exhausts. Rocks are present, however, because one about $2.7 \mathrm{~cm}$ across was purged earlier in the mission (Figure $8 c$ and Table 5, sol 31 ).

\section{Rock Pushing, VL-2}

Rock nudging and pushing were undertaken by VL-2 because samples collected from the newly exposed materials would have been shielded from the sun, which destroys biota and decomposes organic molecules. In view of the fact that the surface sampler was not designed to push rocks, the outcome was remarkably successful. Behavior of the rocks during nudging and pushing varied. Rock 1 (Figure $1 b$ ) did not move, perhaps because it is deeply buried. Rock 3 moved in a complicated way (Figure 10). During the first push (Table 5, sol 34 ), rock 3 probably tilted up, rotated counterclockwise (as

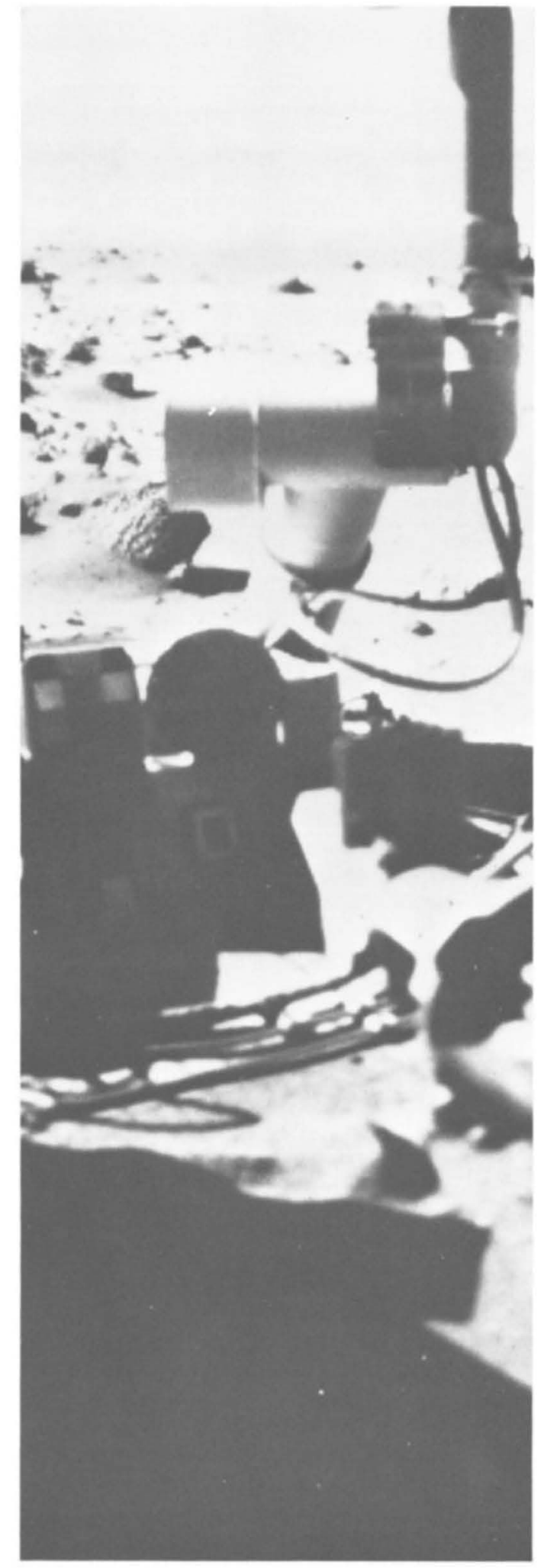

Fig. 7. Conical pile of drift material from Sandy Flats dumped on the lander grid during sequence on sol 41. Material is at angle of repose. (VL-1 camera 1, frame B107; sol 41, 1606:09 LLT; sun elevation, $38.7^{\circ}$; sun is to the left.)

viewed in Figure $1 b$ ), and translated about $6 \mathrm{~cm}$ (Figure $10 b$ ). The second push was accompanied by tilting and skidding as shown by the smooth appearing skid marks (Figure 10c). Rock 7 plowed and furrowed while it was rotating clockwise. 

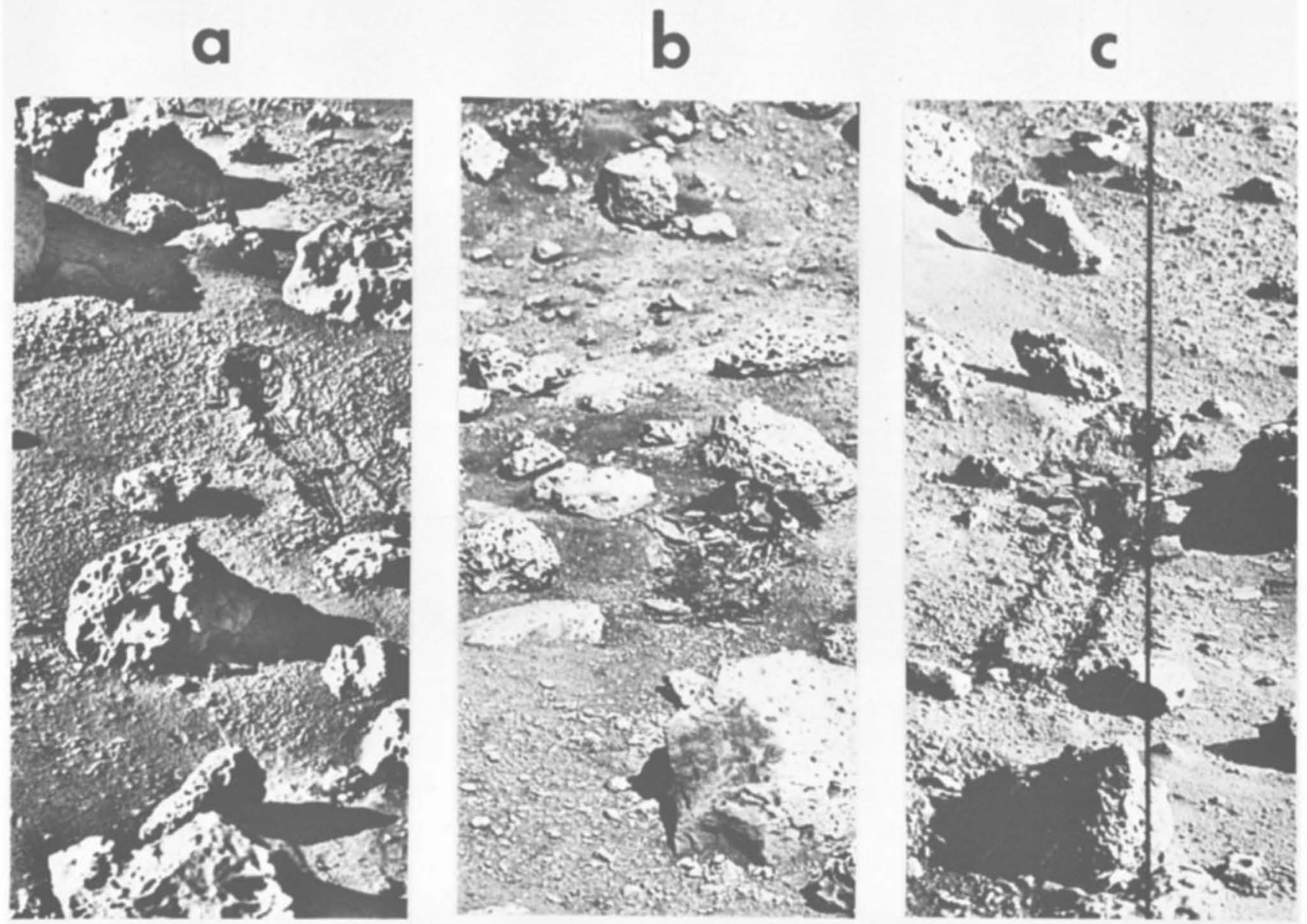

Fig. 8. Three types of trenches excavated by VL-2 during the primary mission. (a) Trench with knobby raised rim dug on sol 8 (Biology 1, VL-2 camera 2, frame A110; sol 15, 1659:59 LLT; sun elevation, 28.9 ; sun is to the left). (b) Trenches with mixed fines and platy fragments dug on sols 21 (GCMS 2) and 29 (XRFS 2) (VL-2 camera 2, frame A242; sol 29, 1419:59 LLT; sun elevation $51.5^{\circ}$; sun is to the right). (c) Trench with blocky fragments dug on sol 57 (XRFS 3, VL-2 camera 2, frame C045; sol 57, 0940:59 LLT; sun elevation, $44.2^{\circ}$; sun is to the right). Dimensions of the trenches are given in Table 5 . The small rock in the lower right corner of $(c)$ was purged by the surface sampler.

Rock 6 merely tipped backward away from the lander. It is noteworthy that none of the rocks spalled or chipped noticeably while they were being nudged and pushed. Forces of about $200 \mathrm{~N}$ were exerted on rock 1 because commanded surface sampler extensions were not achieved when rock 1 failed to move. The teeth of the collector head should have exerted a sizable stress on the rock. The area of a tooth is about $1 \mathrm{~mm}^{2}$, so the stress was of the order of $10^{8} \mathrm{~N} / \mathrm{m}^{2}$. Thus a thick weak weathered rind is not present on that rock.

\section{Samples Under Rocks, VL-2}

Samples were acquired beneath rocks 3 and 6 (Figure $1 b$ ). Very rough estimates of the water evolved during heating were obtained by the Molecular A nalysis experiment. The amount of water evolved by the soil from beneath rock 3 when it was heated from $50^{\circ}$ to $200^{\circ} \mathrm{C}$ is much larger $(0.15-1.1 \%)$ than that evolved from a sample exposed to the sun and heated in one step to $200^{\circ} \mathrm{C}(\sim 0.002 \%)$ [Biemann et al., 1976]. Heating of both samples from $200^{\circ}$ to $350^{\circ} \mathrm{C}$ and then to $500^{\circ} \mathrm{C}$ evolved comparable amounts of water in each step. The Biology Py- rolytic Release results for a sample collected beneath rock 7 (Figure $1 b$ ) are also compatible with relatively large amounts of water [Horowitz et al., 1976]. Larger amounts of water should be expected in samples of soil collected from beneath rocks than in samples of soil exposed to the sun. Field and laboratory studies on earth show that soil beneath rocks in a field of soil has detectably more adsorbed water at depths of 2.5-5.0 $\mathrm{cm}$ than soils exposed to the sun and atmosphere [Jury and Bellantuoni, 1976a, b]. The studies of these authors indicate that the net heat flow is toward the soil beneath the rocks, so that water vapor moves under the thermal gradient toward the area beneath the rocks, where it is cooler on the average than it is elsewhere at shallow depths of $2-5 \mathrm{~cm}$. The rock cap inhibits evaporation. Additionally, ultraviolet radiation causes dehydration of exposed soils [Huguenin, 1976].

\section{Surface Sampler Motor Currents}

Viking surface sampler motor currents were sampled every $0.195 \mathrm{~s}$ with a resolution of $0.039 \mathrm{~A}(4 \mathrm{kbit} / \mathrm{s})$ in the engineering data format (Format 5 ) as the surface sampler collector 

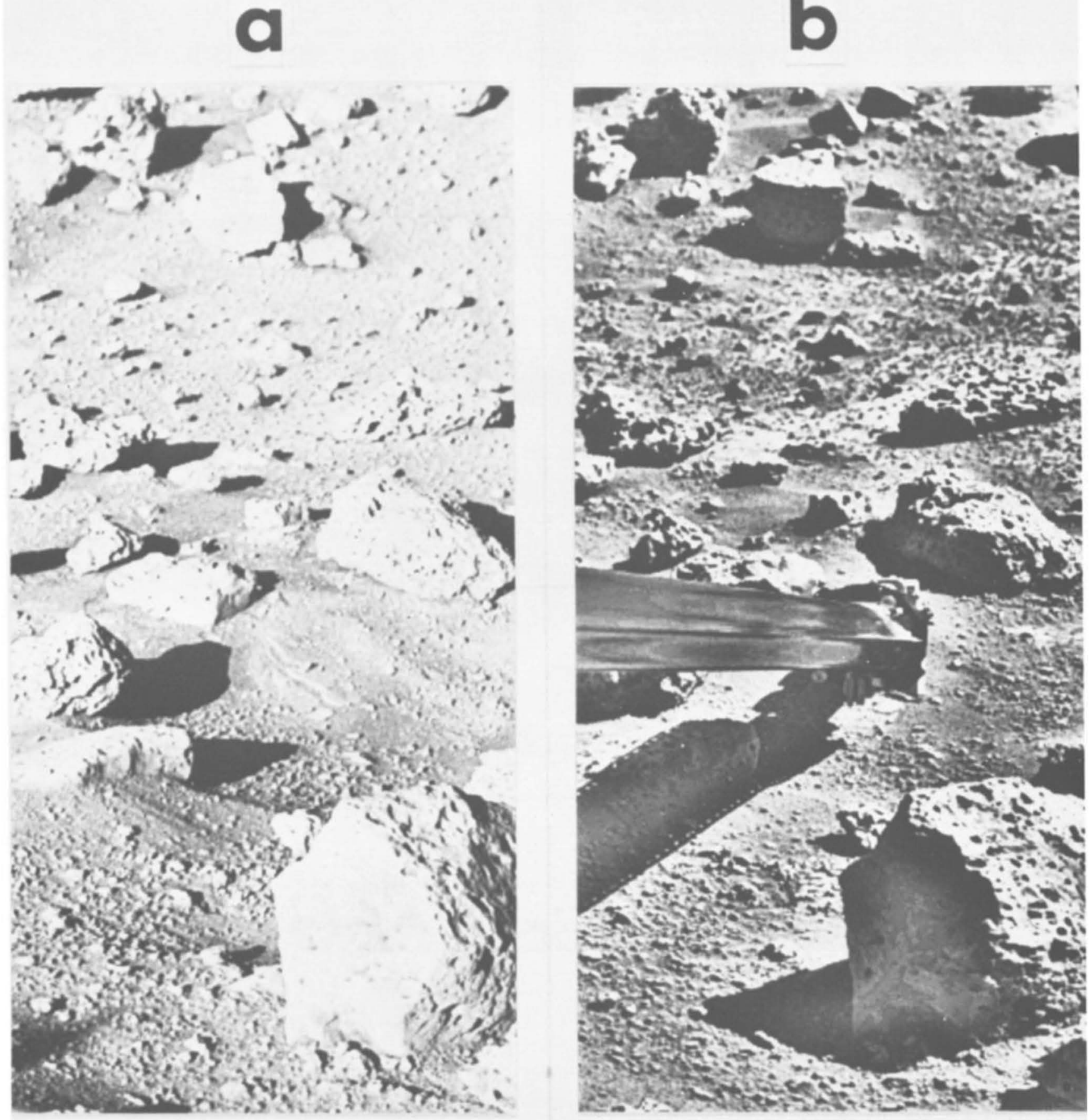

Fig. 9. (a) Bonneville Salt Flats prior to sample acquisitions on sols 21 and 29 (see Figure $8 b$, VL-2 camera 2, frame A005; sol 0, 1729:59 LLT; sun elevation, 25.6 $6^{\circ}$ sun is to the left) and $(b)$ backhoe touchdown picture on sol 21 (VL-2 camera 2, frame A154; sol 21, 1010:58 LLT; sun elevation, $52.2^{\circ}$; sun is to the right). Note that the surface in $(a)$ has been locally stripped of fines to expose a smooth surface of material with open fractures; the backhoe in $(b)$ has penetrated smooth surface material with open fractures about $1 \mathrm{~cm}$; this shows that it is weak. 


\section{a}

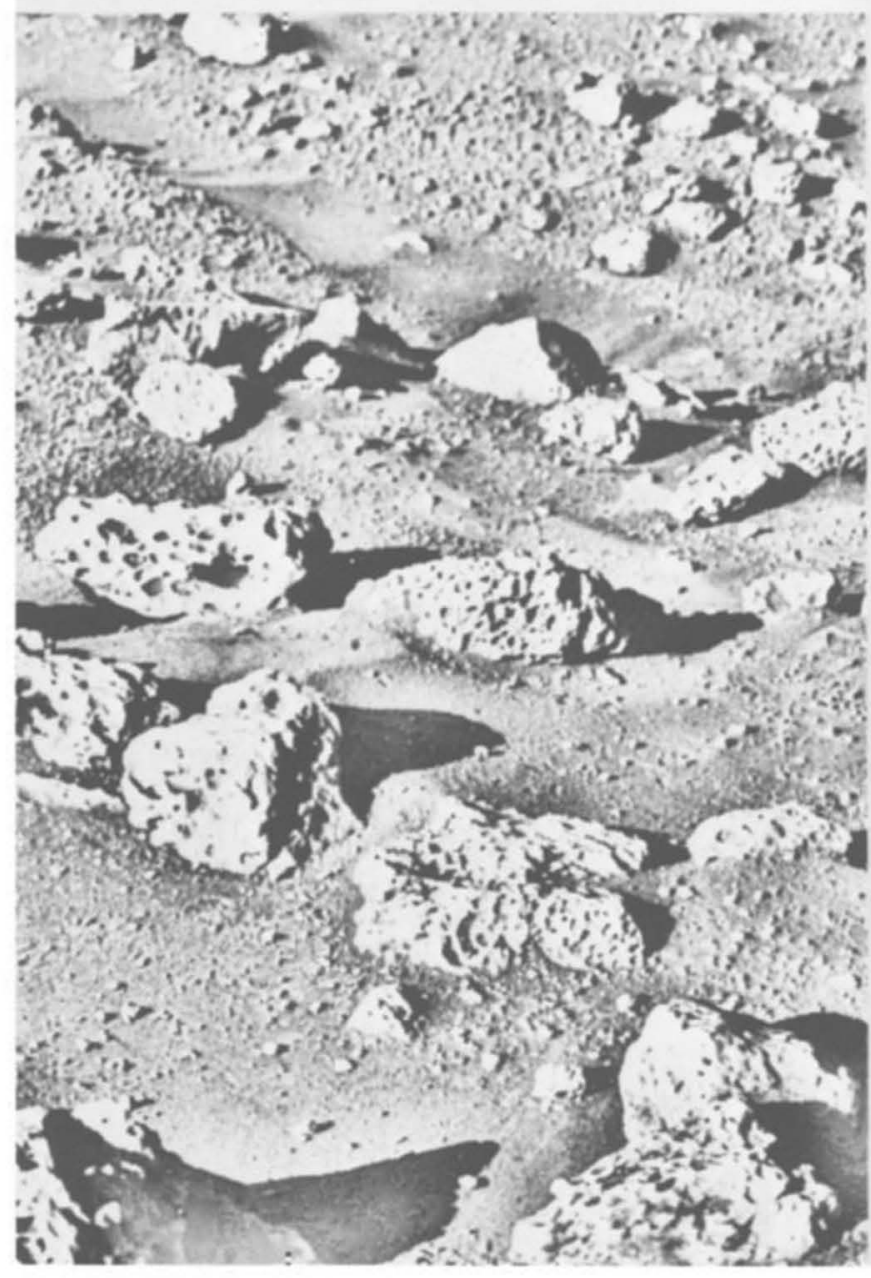

b

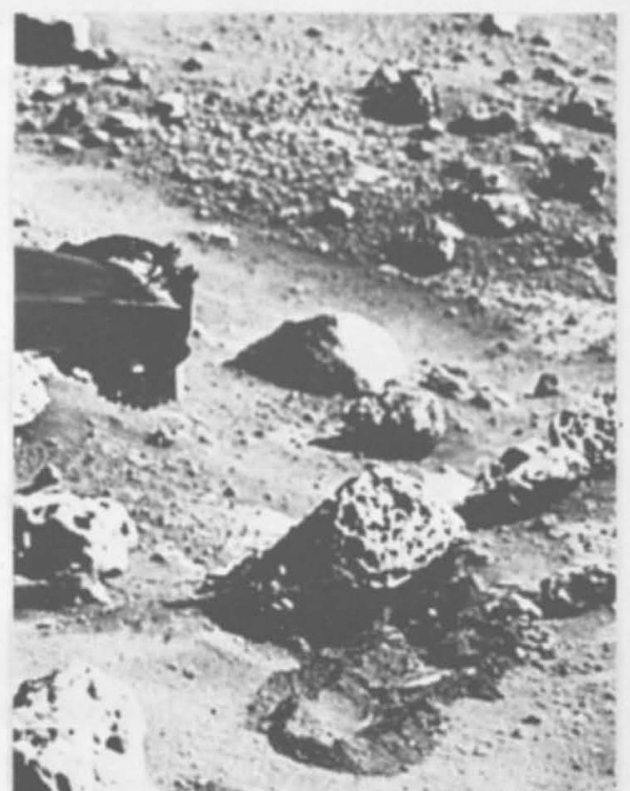

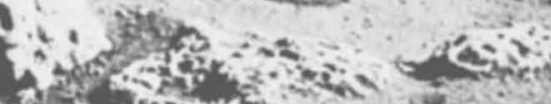

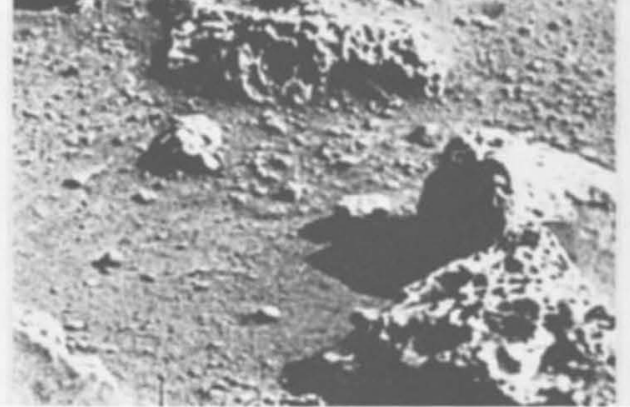

C

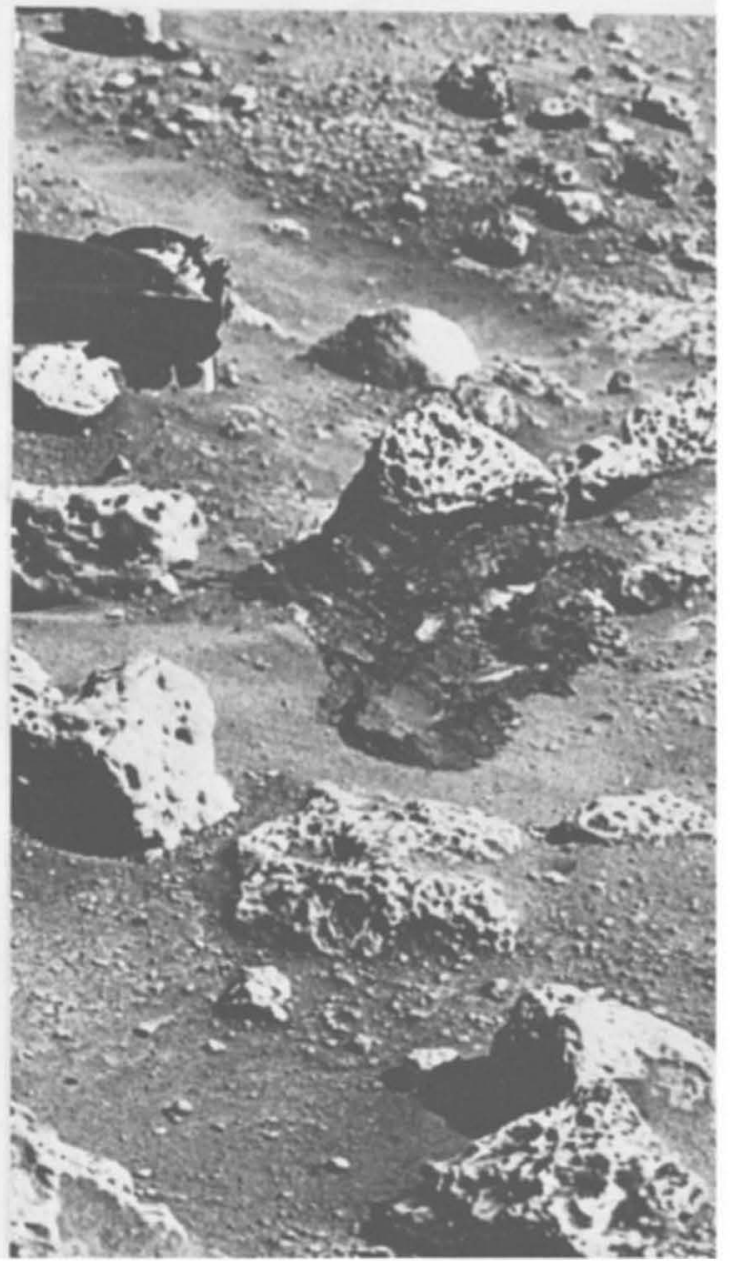

Fig. 10. Sequence of pictures showing the movement of rock 3, which was pushed by VL-2 to collect samples protected from ultraviolet radiation. (a) Rock prior to being pushed (VL-2 camera 2, frame A005; sol 0, 1729:59 LLT; sun elevation, 25. $6^{\circ}$; sun is to the left). (b) Rock after push on sol 34 has rotated it $69^{\circ}$ counterclockwise, tilted it about $40^{\circ}$, and translated it about $6.5-7.0 \mathrm{~cm}$ (VL-2 camera 2, frame B030; sol 34. push on sol 34 has rotated it $69^{\circ}$ counterclockwise, tilted it about $40^{\circ}$, and translated it about $6.5-7.0 \mathrm{~cm}$ (VL-2 camera 2, frame B030; sol 34,
1048: $10 \mathrm{LLT}$; sun elevation, $55.0^{\circ}$; sun is to the right). (c) Rock after push on sol 37 has rotated it $7^{\circ}$ clockwise, tilted it $20^{\circ}$ backward, and 1048: $10 \mathrm{LLT}$; sun elevation, $55.0^{\circ}$; sun is to the right). (c) Rock after push on sol 37 has rotated it 7 clockwise, tilted it $20^{\circ}$ back ward, and
translated it $12-15 \mathrm{~cm}$ away from the lander (VL-2 camera 2, frame B046; sol 37, 1146:21 LLT; sun elevation, $58.6^{\circ}$; sun is to the right). The upper surface of the rock, the layer midway in the rock, and the base show that the rock tilts away from the spacecraft in $(a)$. Note the 'water line' of soil adhering to the left side of the rock in $(b)$; the large trench in $(b)$ was inadvertently formed during retraction of the surface sample because the rock leaned on the surface sampler. Note the smooth surfaces produced by skidding on soil in $(c)$. The sample of soil originally under the rock for Molecular Analysis (GCMS 2) was collected to the left of a long trench that was produced inadvertently. 
head was pushed into the Martian surface materials during some sample acquisitions. After removal of cyclic currents and the base current, forces are related to motor currents and power by using calibration data from tests using flight type hardware [Crouch, 1976]. The resolution in force is about 25 N.

Despite this poor resolution, forces inferred from motor currents are consistent with soils having low cohesions. The surface sampler extends at a rate of about $0.025 \mathrm{~m} / \mathrm{s}$ so that durations of motor currents may be correlated with extension or length of travel as the collector head plows through the surface material.

Forces on Mars exhibit four basic patterns (Figure 11): (1) an initial rise from zero to about $50 \mathrm{~N}$ followed by a rise to $75 \mathrm{~N}$ (Figures $11 a$ and $11 b),(2)$ an initial rise to $50 \mathrm{~N}$ followed by periodic rises to $75 \mathrm{~N}$ (Figures $11 c$ and $11 d$ ), (3) a rapid rise to $75 \mathrm{~N}$ (Figures $11 \mathrm{e}$ and $11 \mathrm{f}$ ), and (4) a steady force of $50 \mathrm{~N}$ (Figure $11 \mathrm{~g}$ ). The final peak force in Figure $11 \mathrm{c}$ was caused by an encounter with a rock. Tests were also conducted with the Science Test lander on earth to gain a clearer understanding of the motor current data. Forces for a sample acquisition into sand are similar to those of type 1 on Mars (Figure $1 \mathrm{~h}$ ). Forces of $50 \mathrm{~N}$ were measured without digging by extending in air (Figure $11 i$ ) and on a smooth metal surface (Figure $11 j$ ). Thus the force during excavation must account for the no-load condition of $50 \mathrm{~N}$ and is $25-50 \mathrm{~N}$ larger than that for the noload condition (compare Figures $11 h$ and $11 j$ ).

Dimensionless equations relating forces on small blades during plowing [Luth and Wismer, 1971; Wismer and Luth, 1972] may be applied to the results for the Science Test lander and Mars with the tacit assumption that soil-to-metal frictions are the same for the surface sampler and plow blades used in the tests to determine the constants in the dimensionless equations. In using the equations for cohesionless sand with an angle of internal friction of $35^{\circ}-37^{\circ}$ (see Figure 12), a plowing depth $z$ of $5.6 \mathrm{~cm}$, a plow or collector head width $b$ of $4.4 \mathrm{~cm}$, a plow height $l$ of $7.6 \mathrm{~cm}$, an angle of attack $\alpha$ of $80^{\circ}$, and a rate of $0.025 \mathrm{~m} / \mathrm{s}$ (see Figure 12 for definitions), forces due to plowing would increase from zero to about $26 \mathrm{~N}$ as the collector head extended into cohesionless sand with a density of $1600 \mathrm{~kg} / \mathrm{m}^{3}$ on earth. For Mars, in using the values above and an acceleration of gravity of $3.78 \mathrm{~m} / \mathrm{s}^{2}$, forces due to plowing would increase from zero to about $10 \mathrm{~N}$. Thus the motor currents and inferred forces for the sols 46 and 47 sample acquisitions are compatible with cohesionless sand having an angle of internal friction near $35^{\circ}-37^{\circ}$. Cohesion could also be present. Near the end of the sol 47 acquisition, forces rose above $75 \mathrm{~N}$, whereas they did not during sol 46. Such a rise in force could be due to buried rocks or local clods with large cohesion. If the increase in force is due to cohesion, dimensionless equations for cohesive frictionless soil (see Figure 12) applied to Martian soils place an upper bound for cohesion near $2 \mathrm{kN} / \mathrm{m}^{2}$.

Motor currents translated into forces for other trenches can also be interpreted within broad limits. Forces inferred for both the Molecular Analysis (GCMS 2, Figure 1b) sample acquisition from under a rock (rock 3, Figure $1 b$ ) and the VL-2 Physical Properties sample acquisition on sol 56 (Physical Properties 1, Figure $1 b$ ) exhibit an oscillatory pattern with values of 50 and $75 \mathrm{~N}$. The collector head tended to skim the surface at shallow depth for both of these trenches because the local surface had relatively large tilts away from the spacecraft (Figures $11 c$ and $11 d$ ). Uniform forces between 50 and $75 \mathrm{~N}$ were observed for the VL-1 Physical Properties sample acquisition on sol 41 (Physical Properties, Figure 1a), which are consistent with a uniform weakly cohesive surface material.

Similar results are inferred for the VL-2 sample acquisition for Inorganic Chemical Analysis (XRFS 1, Figure 1b). The large forces at the end of the current record (Figure 1le) are the result of interaction between the sampler, the soil, and rock 6 (Figure $1 b$ ), which was displaced upward $0.4 \mathrm{~cm}$ at the end of the extension stroke. Unusually low currents for the sample acquisition under rock 7 (Biology 3, Figure $1 b$ ) may be due to a very shallow trench, because stereoscopic pictures do not reveal the presence of a large deep trench.

Although motor currents are not available for the sample acquisitions for Molecular Analysis and Inorganic Chemical Analysis in the rocky area of VL-1 (GCMS 2, XRFS 1 and 2, Figure $(a)$, the commanded extensions were not achieved two out of five times. This means that the sampler motor clutched, and forces of at least $200 \mathrm{~N}$ were exerted on the surface materials there. Using the equations and dimensions above for a cohesive frictionless soil indicates that the cohesion could be $\geq 10 \mathrm{kN} / \mathrm{m}^{2}$. Alternatively, buried rocks could be present. During the first extension for Inorganic Chemical Analysis in the rocky area of VL-1 (XRFS 2, Figure $1 a$ ) the surface sampler failed to reach its full extension, and the resulting trench (Figure $6 b$ ) had an area of disrupted clods and possibly small rocks several centimeters across. This soil behavior is consistent with a relatively large cohesion.

The surface sampler coupled with motor current measurements has not been fully utilized for Physical Properties Investigation at this time. Larger extensions into the Martian surface material with larger depression angles should produce larger forces and currents. This procedure is required to overcome the disadvantage of the poor resolution of $0.039 \mathrm{~A}$ or 25
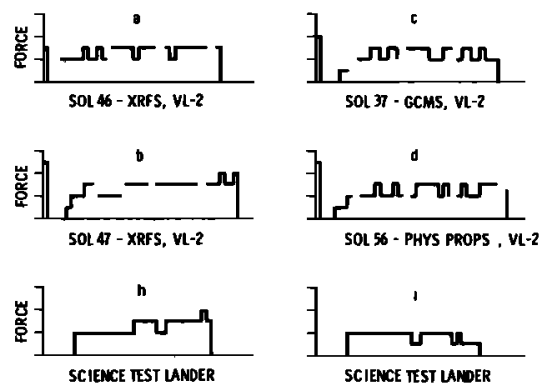
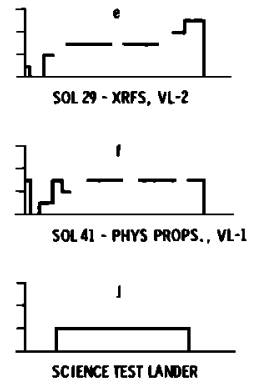
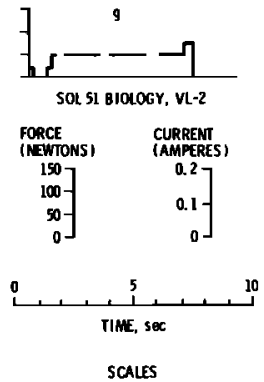

Fig. 11. $(a-g)$ Surface sampler motor currents and forces for sample acquisitions on Mars and $(h-j)$ Science Test lander on earth. Note the similarity in current records of $(a),(b)$, and $(h) ;(c)$ and $(d)$; and $(e)$ and $(f)$. Four types of patterns mentioned in text are shown in $(a)$ and $(b),(c)$ and $(d),(e)$ and $(f)$, and $(g)$. Generalized sampling sequences and conditions for Mars can be found in Tables 4 and 5 by using the sols for the appropriate lander. 

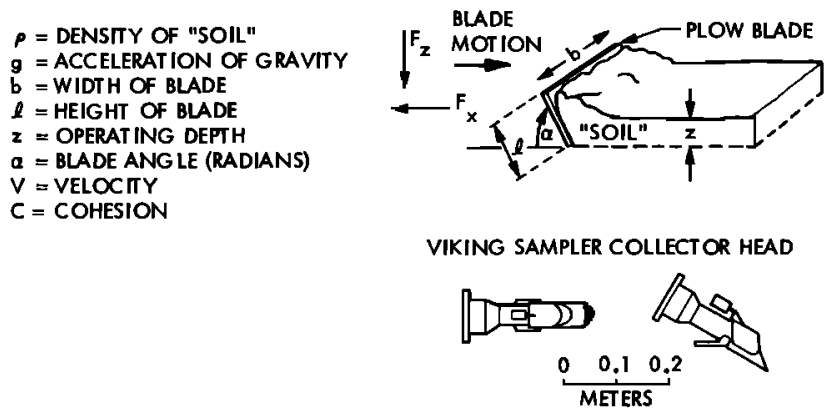

PURE FRICTION

$$
\begin{aligned}
& F_{x}=\rho g b z^{0.5} l^{1.5} a^{1.73}\left[\frac{z}{l \sin \alpha}\right]^{0.77}\left[1.05\left(\frac{z}{b}\right)^{1.1}+1.26 \frac{v^{2}}{g l}+3.91\right] \\
& \left.F_{z}=\rho g b z=.5 l 1.5\left[0.193-(a-0.714)^{2}\right]\left[\frac{z}{l \sin \alpha}\right]^{0.777} \mid 1.31\left(\frac{z}{b}\right)^{0.966}+1.43 \frac{v^{2}}{g l}+5.60\right] \\
& \text { PURE COHESION } \\
& F_{x}=\rho g b z^{0.5} l^{1.5} \alpha^{1.15}\left[\frac{z}{l \sin \alpha}\right]^{1.21}\left[\left(\frac{11.5 C}{\rho g z}\right)^{1.21}\left(\frac{2 V}{3 b}\right)^{0.121}\left(0.055\left(\frac{z}{b}\right)^{0.78}+0.065\right)+0.64 \frac{V^{2}}{g l}\right] \\
& \left.\left.F_{z}=\rho g b z=5 l^{1.5}\left\{0.48-(\alpha-0.70)^{3}\right]\left[\frac{z}{l \sin a}\right]\right\}\left[\left(\frac{11,5 C}{\rho g z}\right)^{0.41}\left(\frac{2 V}{3 b}\right)^{0.041}\left(9.2 \mid \frac{z}{b}\right)^{0.225}-5.0\right)+0.24 \frac{V^{2}}{g l}\right\}
\end{aligned}
$$

Fig. 12. Diagram illustrating plowing model, Viking surface sampler collector head, and dimensionless equations used to calculate expected forces on the collector head during sampling on Mars [Luth and Wismer, 1971; Wismer and Luth, 1972].

$\mathrm{N}$ of force. When this occurs in the extended mission, better estimates of cohesions and angles of internal friction of the surface materials will be possible.

\section{Soil Adhesion}

On sol 8 a picture taken of the collector head after it acquired a sample from a rather deep trench in Sandy Flats showed drift material adhering everywhere on the collector head. After this sample and a subsequent sample were delivered to Inorganic Chemical Analysis, and after the coarse fraction had been purged on sol 8, a second picture was acquired from the rather shallow trench on sol 14 (Figure $6 a$ ), and during retraction a malfunction occurred causing the collector head to stop. A picture of the collector head taken on sol 20 to discover the cause of the malfunction showed drift material adhering to the lower part of the collector head, but the upper part was clean, a result of the shallow excavation. The sample was delivered to Molecular Analysis on sol 22, and pictures of the collector head taken on sol 24 showed that it was again free of adhering drift material. Thus the adhering drift material had survived winds up to $15 \mathrm{~m} / \mathrm{s}$ and boom oscillation during elevation from the surface, but vibrations of 8.8 and $4.4 \mathrm{~Hz}$ of the collector head upper jaw during sample delivery and purging removed the material. Natural boom frequencies for the extension ( 90.2 inches, or $229 \mathrm{~cm}$ ) during elevation after sampling is $2.1 \mathrm{~Hz}$. Tests simulating delivery and purge of the sol 14 sample on sol 22 using flight type hardware produced accelerations $a$ of $118-529 \mathrm{~m} / \mathrm{s}^{2}$. For grains $0.01 \mathrm{~cm}$ across (diameter $d$ ) with a density $\rho$ of 1500 $\mathrm{kg} / \mathrm{m}^{3}$ the upper limit of adhesive stress $\sigma$, which strongly depends on the assumed grain size, is

$$
\sigma=p d a=79 \mathrm{~N} / \mathrm{m}^{2}
$$

Accelerations produced by the extended boom ( 90.2 inches, or $229 \mathrm{~cm}$ ) during elevation after sampling are accompanied by 1.3- to $1.9-\mathrm{cm}$ displacements at $2.1 \mathrm{~Hz}$, so accelerations of 2.3 $\mathrm{m} / \mathrm{s}^{2}$ are indicated. Peak accelerations are $2.3 \mathrm{~m} / \mathrm{s}^{2}$ plus the acceleration due to gravity $\left(3.8 \mathrm{~m} / \mathrm{s}^{2}\right)$ for a total of $6.1 \mathrm{~m} / \mathrm{s}^{2}$. Lower bound stresses are then $0.9 \mathrm{~N} / \mathrm{m}^{2}$. Thus the adhesion of the Martian soil is in the range of $0.9-79 \mathrm{~N} / \mathrm{m}^{2}$ if the grain size is in fact $0.01 \mathrm{~cm}$.

\section{Surface Temperature Measurements}

The parachute phase [Nier et al., 1976] ambient temperature sensors on VL-1 and VL-2 survived the shock of touchdown. The sensor is located on the inboard perimeter of footpad 2. Figures $13 a$ and $13 b$ show temperature plots of this sensor for both landers. The main leg support and secondary supports as well as other lander body parts cast shadows across the temperature sensor at different times during a sol. This fact resulted in a complicated insolation function for both landers. In the case of VL-1 footpad 2, which penetrated about $16 \mathrm{~cm}$ into the surface (see Figure $2 b$ ), however, it required a series of pictures taken by the boom-mounted mirror to determine that the temperature sensor was partially covered with surface material. This accounts for the elevated temperature curve compared with the predicted $(H$. H. Kieffer, personal communication, 1976) surface temperatures. In the case of VL-2, footpad 2 was not buried and only penetrated about $3 \mathrm{~cm}$. It is unlikely that the sensor is in contact with the surface. Pictures of the temperature sensor have not yet been obtained on footpad 2 on VL-2 to verify this. If the shadow (see Figure $13 b$ ) were 


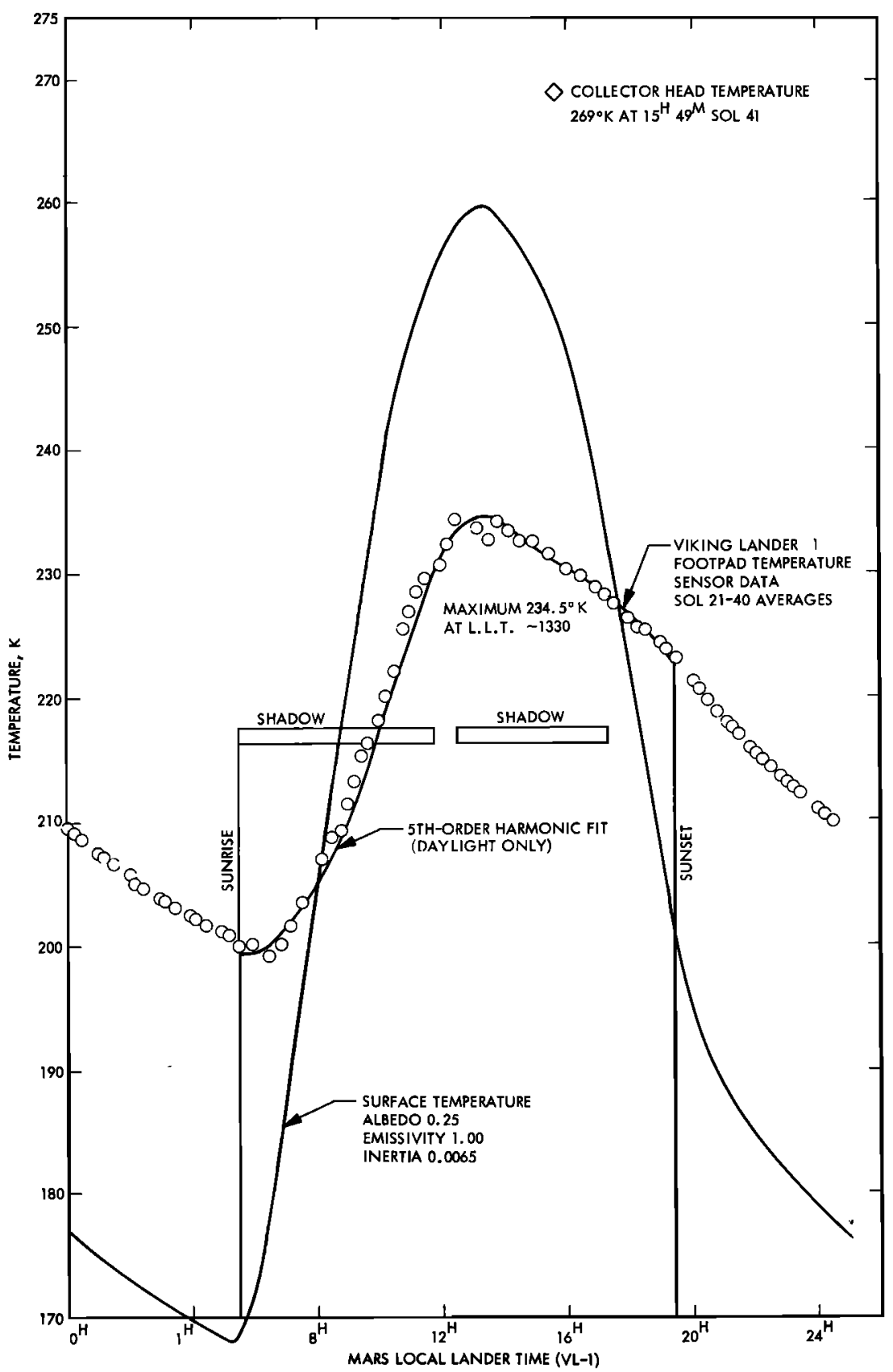

Fig. $13 a$

Fig. 13. Footpad 2 temperature sensor plots. Each open circle is an average of from one to ten readings. (a) VL-1 temperatures averaged over sol 21 through sol 40 for each 6-min interval. The point at 1530:00 LLT was obtained by the collector head after being in the soil for $10 \mathrm{~min}$. (b) VL-2 temperatures averaged over sol 1 through sol 10 for each 6-min interval. The point at 1433:12 LLT was obtained by the collector head after being in the soil for 17 min. Solid curves are expected temperatures (H. H. Kieffer, personal communication, 1976). Times at which sensors were in shadow are shown by open bars.

removed, the temperature curve would probably peak slightly higher than $260^{\circ} \mathrm{K}$, so it is unlikely that it is covered with surface material. Analysis of the temperature data from VL-1 and VL-2 footpad temperature sensors for the primary and extended missions will be reported elsewhere.

In addition to the footpad temperature sensor, there is a thermocouple on the bottom of the collector head intended to show that a soil sample did not reach a value in excess of $20^{\circ} \mathrm{K}$ above the maximum predicted surface temperature. A temperature reading was obtained each time the surface sampler boom or collector head was given a command. Upon the command to close the collector head jaws, readings were ob- tained 2 and $4 \mathrm{~s}$ later. The time constant of the thermocouple was of the order of $8 \mathrm{~min}$, so the reading may be in doubt. Experiments were performed with the collector head buried several centimeters on VL-1 and just barely below the surface on VL-2 for $10 \mathrm{~min}$ or more. It is noteworthy that the collector head temperature of VL-2 was $272^{\circ} \mathrm{K}$ just before it was extended on the surface, next rose to $273^{\circ} \mathrm{K}$ after it was extended on the surface, and then declined to $270^{\circ} \mathrm{K}$ just after it was elevated from the surface. These values are plotted in Figure 13 for both landers. Since the thermocouple is physically bonded to the bottom of the collector head, conduction effects may be significant. 


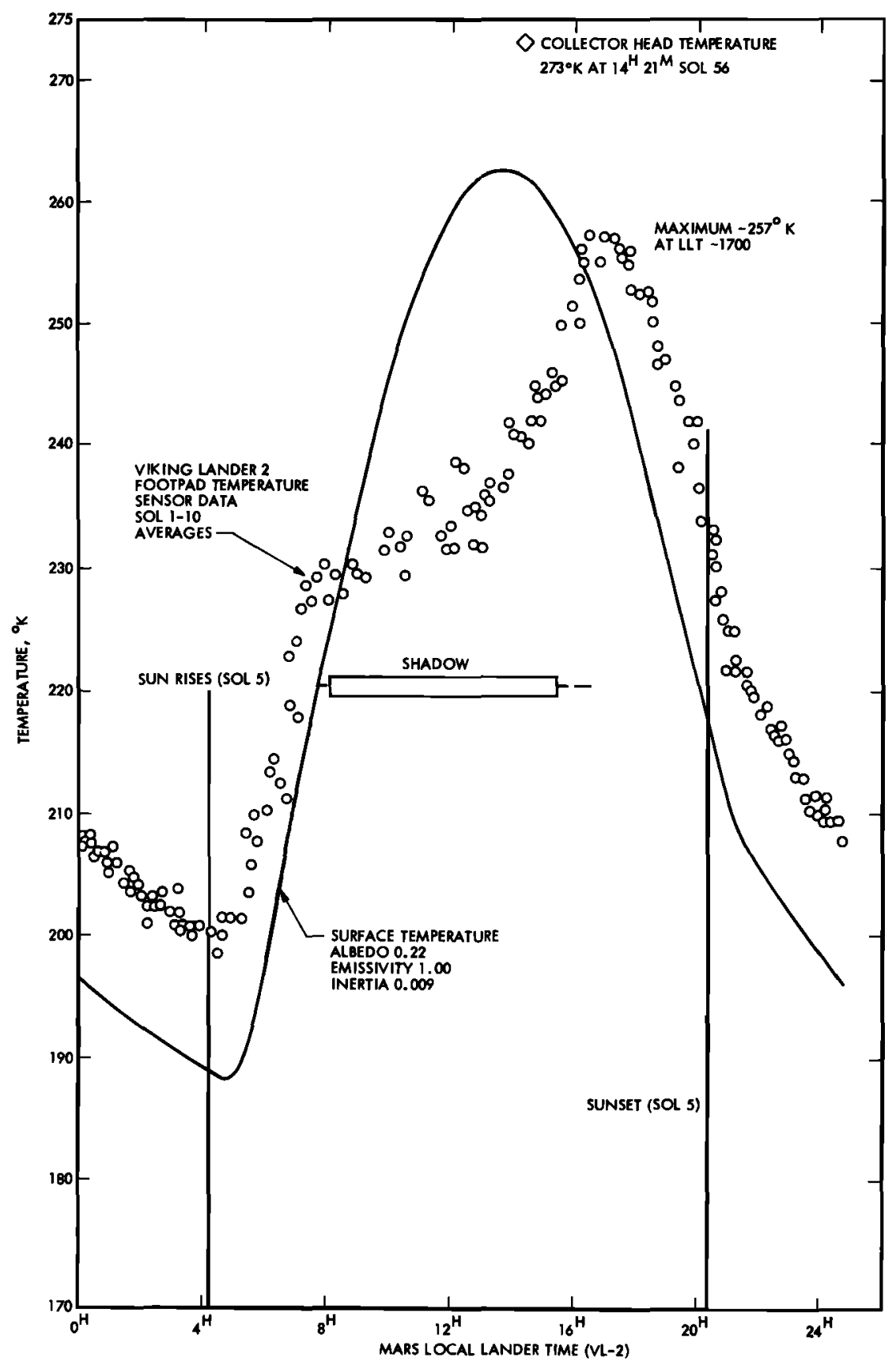

Fig. $13 b$

\section{CONCLUDING REMARKS}

Characteristics of terrestrial soils are commonly described in terms of bulk density, particle size, angle of internal friction, cohesion, and moisture content. Surface materials of Mars at the Viking sites have a broad spectrum of values for these characteristics. At VL-1, there is the relatively weak drift material, along with more cohesive materials of the rocky area, and rocks. A variety of materials are present at the VL-2 site also. Moisture content is low in comparison to terrestrial soils. Current estimates of some of the physical properties are given in Table 6 and discussed below.

\section{Bulk Density}

Bulk densities of the surface materials of Mars cover the range commonly found in natural terrestrial materials. Drift material delivered to Inorganic Chemical Analysis has a bulk density near $1100 \mathrm{~kg} / \mathrm{m}^{3}$ in the disturbed state. In situ densities could range from somewhat higher to somewhat lower than this by a small amount. Penetration by footpad 2, under the assumptions that results can be scaled by using low-velocity impact equations and that there is no hard substrate, lends some support to the notion that the in situ density is slightly larger than $1100 \mathrm{~kg} / \mathrm{m}^{3}$, say, near $1300-1400 \mathrm{~kg} / \mathrm{m}^{3}$. A similar conclusion is reached from the craters produced by grains and fragments propelled by engine exhausts. The coarse fraction of cohesive material from Rocky Flats has a disturbed density near $600 \mathrm{~kg} / \mathrm{m}^{3}$ in the XRFS chamber. If the sample in the chamber is $50 \%$ voids and $50 \%$ clods, the density of the clods is about $1200 \mathrm{~kg} / \mathrm{m}^{3}$. At least some of the fragments disrupted during the sol 29 acquisition are probably clods, and engine exhaust erosion exposed a fractured cohesive surface, so it 
TABLE 6. Current Best Estimate of Soil Properties Deduced from Viking 1 and Viking 2 Data

\begin{tabular}{lccc}
\hline \multicolumn{1}{c}{ Property } & \multicolumn{2}{c}{ VL-1 } & \\
\cline { 2 - 3 } & Sandy Flats & Rocky Flats & VL-2 \\
\hline $\begin{array}{l}\text { Bulk density, } \mathrm{kg} / \mathrm{m}^{3} \\
\quad \text { Soil }\end{array}$ & $1000-1600$ & $1200-1600$ & $1100-1480$ \\
$\quad$ Rock & & 2900 & 2600 \\
Particle size, $\%$ & 0 & 25 & 20 \\
$\quad>2 \mathrm{~cm}$ & 100 & 75 & 80 \\
$\quad$ Clods and fines & $10-10^{2}$ & $10-10^{4}$ & $10-10^{3}$ \\
Cohesion of soil, N/m & $\ldots$ & $>10^{4}$ & $>10^{4}$ \\
Cohesion of rock, $\mathrm{N} / \mathrm{m}^{2}$ & $30-45$ & $30-45$ & $30-45$ \\
Angle of internal friction, deg & $3 \times 10^{5}$ & $6 \times 10^{\circ}$ & $6 \times 10^{8}$ \\
Penetration resistance, $\mathrm{N} / \mathrm{m}^{2} / \mathrm{m}$ & $1-10^{2}$ & $\ldots .3$ & $\ldots$ \\
Adhesion, $\mathrm{N} / \mathrm{m}^{2}$ & $0.3-0.5$ & $0.3-0.5$ & $\ldots$ \\
Coefficient of sliding friction & & & $\ldots$ \\
\hline
\end{tabular}

Particles as used here include clods as well as individual mineral and rock grains; thus the estimates of particle sizes must be considered approximate and preliminary. The frequency of rocks $10 \mathrm{~cm}$ and larger at VL-2 is twice as large as that at VL-1 (Figures 1 and 2). The estimated density of materials after delivery to the XRFS experiment is $1.1 \pm 0.15 \mathrm{~g} / \mathrm{cm}^{3}$. The estimates may be revised at a future date.

seems likely that in situ bulk densities of this material are near $1200 \mathrm{~kg} / \mathrm{m}^{3}$. Since the Rocky Flats sample came from between larger rocks, the bulk density of the whole rocky area will be larger. For a material with $25 \%$ rocks with densities of 2900 $\mathrm{kg} / \mathrm{m}^{3}$ and $75 \%$ matrix with a density of $1200 \mathrm{~kg} / \mathrm{m}^{3}$ the bulk density of the entire rocky soil would be $1625 \mathrm{~kg} / \mathrm{m}^{3}$. For comparison, reflection coefficients of terrestrial radar imply a density near $2000 \mathrm{~kg} / \mathrm{m}^{3}$ for the Chryse region near the landing site [Tyler et al., 1976]. Quantitative data for a more rigorous detailed comparison of lander and radar results are not yet available.

Densities of samples of fines determined by Inorganic Chemical Analysis by VL-2 are comparable to those of VL-1 (B. Clark, personal communication, 1977). Because about $20 \%$ of the sample field is covered by rocks, the bulk density of the entire material at VL-2 would be higher. If $20 \%$ of the volume of the material is rocks with a density of $2600 \mathrm{~kg} / \mathrm{m}^{3}$ (because they may be vesicular) and the remaining is matrix with a density of $1200 \mathrm{~kg} / \mathrm{m}^{3}$, the density of the whole would be 1480 $\mathrm{kg} / \mathrm{m}^{3}$.

The Inorganic Chemical Analysis indicates that the surface materials may be montmorillonite clays [Baird et al., 1976]. If this is the case, individual mineral grains composing the fines at both landing sites should be comparable to those of montmorillonite clays on earth. These are typically $2500-2600$ $\mathrm{kg} / \mathrm{m}^{3}$.

\section{Particle Size}

Again large variations are present at both sites. Rocks several meters across occur in the field of view of both landers. Rocks several centimeters in size are also found in the field of view at both landers. One rock, $2.7 \mathrm{~cm}$ across, was purged by VL-2. Many of the objects seen in the lander pictures a few millimeters across to several centimeters are clods as proved by the repeated attempts to collect rocks. In most cases, small clods and rocks cannot be separated visually from one another in the pictures. Local smoothing and tamping of disturbed material that produces highly reflective surfaces is consistent with granular material that is silt size and smaller.

\section{Cohesion}

Cohesion of the drift material of VL-1 determined from the relief of marginally stable trench walls is in the range of $10-10^{2}$
$\mathrm{N} / \mathrm{m}^{2}$. Failure of the surface sampler of VL-1 to reach its commanded extension at Rocky Flats combined with estimates of forces required for plowing suggests that cohesions there may exceed $10^{4} \mathrm{~N} / \mathrm{m}^{2}$, but locally they are lower. A large cohesion and relatively large bulk density of the rocky material are consistent with the small penetration by footpad 3 of VL-1. Penetration by footpad 3 by all criteria is substantially smaller than would be expected for a lunar nominal soil with a cohesion of $10^{3} \mathrm{~N} / \mathrm{m}^{2}$ and a density of $1600 \mathrm{~kg} / \mathrm{m}^{3}$. Thus it seems likely that the cohesion of the rocky area may be rather large. Soil between the rocks at VL-2 probably has a cohesion near 2 $\times 10^{9} \mathrm{~N} / \mathrm{m}^{2}$, but it could be less at least locally. Support for a cohesion near $10^{3} \mathrm{~N} / \mathrm{m}^{2}$ comes from the backhoe touchdown picture on sol 21 as well as surface sampler motor currents. The rocks at both sites clearly have very large cohesion, but measurement is not possible. Considerable strength for the rocks is implied by the attempt to push rock 1 . Stresses exerted by the sampler collector head teeth must have exceeded $\sim 10^{8}$ $\mathrm{N} / \mathrm{m}^{2}$, but they were not large enough to chip or spall the rock.

\section{Angle of Internal Friction}

Careful analyses of deformations around trenches have not been made at this time, so the angles of internal friction that appear in Table 6 are based on rough estimates. Deformations and disruption of the soils extend considerable distances from a number of the trenches. Topographic evidence indicates that the surface was domed out to at least $10 \mathrm{~cm}$ from the rim of the sol 8 trench of VL-1 (Figure 6) and $7-8 \mathrm{~cm}$ in the lateral directions. Similar results for the sol 8 trench and other trenches show that the soils fail by general shear and have internal friction. The pile of drift material deposited on the grid of VL-1 (Figure 7) has slopes slightly larger than $39^{\circ}$, implying that an angle of internal friction in the loose state [Terzaghi, 1943] is near but somewhat larger than $39^{\circ}$.

\section{Aeolian Transportability}

Four observations on the physical properties of the Martian surface place constraints on aeolian processes: (1) the surface materials have cohesion, (2) engine exhausts transported surface materials, (3) material deposited on the body of VL-1 has been winnowed away by the wind, and (4) the profusion of rocks on the surface should affect the near-surface wind velocity gradients. Cohesion of the drift material of the VL-1 site 
and interrock fines at both sites indicate that the threshold wind velocity required to initiate grain motion will pass through a minimum just as terrestrial soils have a minimum [Bagnold, 1941]. Readily entrained very fine grained cohesionless soils [Sagan and Bagnold, 1975] are absent at the Viking landing sites and perhaps Mars. Additional products of cohesion are aggregates and clods of soils which require rather complicated aeolian transport models for the soils (see, for example, Chepil and Woodruff [1963]). Indeed, areas where surface fines at the VL-2 site have been stripped away to expose fractured and blocky soil units are similar to surfaces of underlying clay exposed during terrestrial tests [Chepil and Woodruff, 1963]. A final result of cohesion is the possibility that Martian dunes are made of aggregates and clods instead of mineral grains and rocky fragments.

The quantitative aspects of engine exhaust erosion have not yet been fully explored. It is clear, however, that the surface materials are erodible and can be transported. Soil deposited on the body of VL-1 has been eroded and winnowed away by the wind. Thus it is probable that the dunelike structures seen at both landing sites are in fact a result of aeolian transport.

Ubiquitous large blocks observed by both landers should substantially contribute to the stability of the rocky surfaces to wind erosion by altering the near-surface velocity gradient in a complicated way [Chepil and Woodruff, 1963]. Erosive effects of impacts of saltating grains along flat trajectories should be substantially reduced or even eliminated at times by the blocks. Such a process would tend to abrade the rocks and leave an indurated rock surface.

\section{Volatiles}

The large amounts of water (for Mars) evolved during heating as part of the Molecular Analysis experiment lend strong support to models requiring storage of water in the Martian regolith [Fanale, 1976; Huguenin, 1976]. Water evolved from the sample under rock 3 at the VL-2 site during heating from $50^{\circ}$ to $200^{\circ} \mathrm{C}$ may represent adsorbed water. If this is the case and Mars is like the earth, adsorbed water may be present at larger depths, where it is cooler. Thus the Martian regolith may contain substantial amounts of chemically bound and adsorbed water.

\section{Temperatures}

Although they have not been fully analyzed, footpad 2 temperatures and collector head temperatures of the Martian soil lie well above the predicted curves. Footpad 2 temperature sensors of VL-1, which are immersed in soil from 0.2 to $1.5 \mathrm{~cm}$, are $30^{\circ} \mathrm{K}$ higher just before sunrise than the predicted curves. Since temperatures are approximately corrected for spacecraft-related conduction, the difference is significant. A similar result is found for the unburied footpad 2 temperature sensor for $\mathrm{VL}-2$, for which temperatures are $10^{\circ} \mathrm{K}$ higher than the predicted curve just before sunrise. Collector head temperatures are likewise higher than the predicted curves. For VL-2 the collector head temperatures are roughly $10^{\circ} \mathrm{K}$ higher than the predicted curve.

It is noteworthy that the collector head temperature of VL-2 reached $273^{\circ} \mathrm{K}$ or very close to the temperature of the triple point of water. Since surface pressures are substantially greater than 6 mbar [Seiff and Kirk, 1976], it is entirely possible that pressure-temperature conditions at the upper surface of Mars are in the stability field of liquid water for short periods of time and in local areas. This suggests that near-surface freeze-thaw cycles may exist. Perhaps more data on surface temperatures using the collector head temperature sensor can be obtained during the extended mission.

Acknowledgments. We acknowledge the continuing aid and support given to the Physical Properties Investigation Team by the Surface Sampler Team, L. V. Clark, D. S. Crouch, L. K. Schwab, K. Z. Bradford, and W. DeShazor. The Imaging Team kindly furnished the images used in this report. We thank R. B. Hargraves, D. W. Collinson, and E. C. Morris, who gave us able assistance throughout the mission. S. Liebes, Jr., provided the mensuration data for the rock pushes and nudges. We also thank I. M. Mack for her assistance as the Physical Properties intern during the month of August and P. Duffy for his assistance for the month of September. For typing the manuscript several times and for attending to many administrative matters we thank L. Crafton. We appreciate the support of R. Goldstein during sol 0 for VL-I and VL-2 and throughout the mission. We also thank A. Castro and V. Gillespee for their additional support. The help of H. Zimmer and G. Neukum during the acquisition of data is appreciated. The trajectory data were kindly furnished by A. Fontana, F. W. Hopper, J. T. Findley, and J. W. Gerschultz. We acknowledge the help and assistance of S. Dwornik, particularly at the beginning of the project when the Physical Properties Investigation first started. W' are especially appreciative of the assistance of $P$. Cates during the primary mission and particularly during the extended mission. Finally, the Physical Properties Team wishes to express its sincere 'thank you' to the project manager, Jim Martin; the mission director, Tom Young; and the project scientist, G. A. Soffen, for their untiring dedication to the goals of the mission, which maximized the science return. This work was supported by NASA contract NASI-12705 to the Geospace Sciences Laboratory of the University of Utah Research Institute, NASA order L-9714 to the U.S. Geological Survey, and NASA contract NAS1-10534 to TRW Systems, Inc.

\section{REFERENCES}

Bagnold, R. A., The Physics of Blown Sand and Desert Dunes, 265 pp., Methuen, London, 1941.

Baird, A. K., P. Toulmin III, B. C. Clark, H. J. Rose, Jr., K. Kell, R. P. Christian, and J. L. Gooding, Mineralogic and petrologic implications of Viking geochemical results from Mars: Interim report, Science, 194, 1288, 1976.

Biemann, K., et al., Composition of the atmosphere and search for organic compounds at the Martian surface (abstract), Eos Trans. $A G U, 57,945,1976$.

Chepil, W. S., and N. P. Woodruff, The physics of wind erosion and its control, Advan. Agron., 15, 211, 1963.

Clark, B. C., A. K. Baird, H. J. Rose, Jr., P. Toulmin III, K. Keil, A. J. Castro, W. C. Kelliher, C. D. Rowe, and P. H. Evans, Inorganic analysis of Martian surface samples at the Viking landing sites, Science, 194, 1283, 1976.

Clark, L. V., Effect of ambient pressure on Viking Lander footpad penetration in nominal lunar soil, Lett. 159. Viking Proj. Office, NASA Langley Res. Center, Hampton, Va., Oct. 12, 1971.

Clark, L. V., and J. L. McCarty, The effect of vacuum on the penetration characteristics of projectiles into fine particles, NASA Tech. Note, D-15/9, 1963.

Clark, L. V., D. S. Crouch, and R. D. Grossart, Viking '75 Project summary of primary mission surface sampler operations, Doc. VFT019, 477 pp., Viking Flight Team, NASA Langley Res. Center, Hampton, Va., 1977.

Crouch, D. S., PTC surface sampler boom loading test with Format 5 and SSCA TM data, Lett. SST-I7870-DCS, Martin Marietta Corporation, Littleton, Colo., June 25, 1976.

Fanale, F. P., Martian volatiles: Their degassing history and geochemical fate, Icarus, 28, 179, 1976.

Horowitz, N. H., G. L. Hobby, and J. S. Hubbard, The Viking carbon assimilation experiments: Interim report, Science, 194, 1321, 1976.

Huguenin, R. L., Mars: Chemical weathering as a massive volatile sink, Icarus, 28, 203, 1976.

Jury, W. A., and B. Bellantuoni, Heat and water movement under surface rocks in a field of soil, I, Thermal effects, Soil Sci. Soc. Amer. J., 40, 505, $1976 a$.

Jury, W. A., and B. Bellantuoni, Heat and water movement under surface rocks in a field of soil, II, Moisture effects, Soil Sci. Soc. Amer. J., 40, 509, $1976 b$.

Luth, H. J., and R. O. Wismer, Performance of plane soil cutting blades in sand, Trans. ASAE, 14, 255, 1971. 
Martin Marietta Corporation, Footpad soil penetration tests, 1, Data summary, Rep. VER-188, Littleton, Colo., 1971.

Martin Marietta Corporation, Structures and mechanisms design data book, Rep. VER-273, Littleton, Colo., 1973a.

Martin Marietta Corporation, Surface sampler collector head assembly, Drawing 837J.5500100, Littleton, Colo., 19736.

Martin Marıetta Corporation, Entry data analysis for Viking landers 1 and 2, Final Rep. TN 3770 218, Littleton, Colo., 1976.

Mutch, T. A., R. E. Arvidson, A. B. Binder, F. O. Huck, E. C. Levinthal, S. Liebes, Jr., E. C. Morris, D. Nummedal, J. B. Pollack, and C. Sagan, Fine particles on Mars: Observations with the Viking 1 lander cameras, Science, 194, 87, 1976a.

Mutch, T. A.. S. U. Grenander, K. L. Jones, W. Patterson, R. E. Arvidson, E. A. Guiness, P. Avrin, C. E. Carlston, A. B. Binder, C. Sagan, E. W. Dunham, P. L. Fox, D. C. Pieri, F. O. Huck, C. W. Rowland, G. R. Taylor, S. D. Wall, R. Kahn, E. C. Levinthal, S. Liebes, Jr., R. B. Tucker, E. C. Morris, J. B. Pollack, R. S. Saunders, and M. R. Wolf, The surface of Mars: The view from the Viking 2 lander, Science, 194, 1277, 1976b.

National Aeronautics and Space Administration, Viking '75 Project, Viking mission definition, Rep. M 75-123-I (RS-3703001), Append. $D$, p. 35, Vıking Proj. Office, NASA Langley Res. Center, Hampton, Va., 1970.

Nier, A. O., W. B. Hanson, A. Seiff, M. B. McElroy, N. W. Spencer, R. J. Duckett, T. C. D. Knight, and W. S. Cook, Composition and structure of the Martian atmosphere: Preliminary results from Viking 1, Science, 193, 786, 1976.

Pyrz, A. P., Gravity effects on low velocity penetration of a projectile into a cohesionless medium, Rep. GSF/MC/69-6, School of Engineering, Wright-Patterson Air Force Base, Ohio, 1969.

Romine, G. L., T. D. Reisert, and J. Gliozzi, Site alteration effects from rocket exhaust impingement during a simulated Viking Mars landing, NASA Contract. Rep. CR-2252, 1973.

Sagan, C., and R. A. Bagnold, Fluid transport on earth and aeolian transport on Mars, Icarus, 26, 209, 1975.
Scott, R. F., Principles of Soil Mechanics, Addison-Wesley, Reading, Mass., 1963.

Seiff, A., and D. B. Kirk, Structure of Mars' atmosphere up to 100 kilometers from the entry measurements of Viking 2, Science, 194 , 1300, 1976.

Shorthill, R. W., R. E. Hutton, H. J. Moore, and R. F. Scott, Martian physical properties experiments: The Viking Mars lander, Icarus, 16. $217,1972$.

Shorthill, R. W., R. E. Hutton, H. J. Moore, R. F. Scott, and C. R. Spitzer, Physical properties of the Martian surface materials from the Viking 1 lander: Preliminary results, Science, 193, 805, $1976 a$.

Shorthill, R. W., H. J. Moore, R. F. Scott, R. E. Hutton, S. Liebes, Jr., and C. R. Spitzer, The 'soil' of Mars (Viking 1), Science, 194, 91, $1976 b$.

Shorthill, R. W., H. J. Moore, R. E. Hutton, R. F. Scott, and C. R. Spitzer, The environs of Viking 2 lander, Science, 194, 1309, $1976 c$.

Soflen, G. A., Scientific results of the Viking missions, Science, 194, $1274,1976$.

Terzaghi, K., Theoretical Soil Mechanics, John Wiley, New York, 1943.

Tyler, G. L., D. B. Campbell, G. S. Downs, R. R. Green, and H. J. Moore, Radar characteristics of the Viking 1 landing sites, Science, 193. 812, 1976.

Wismer, R. D., and H. J. Luth, Performance of plane cutting blades in clay, Trans. ASAE, I5, 211, 1972.

Young, C. W., The development of empirical equations for predicting depth of an earth-penetrating projectile, Develop. Rep. SC-DR-6760, Sandia Corp., Albuquerque, N. Mex., 1967.

(Received March 31, 1977;

revised May 23, 1977;

accepted May 24, 1977.) 